\title{
On the long-run dynamics of income and wealth inequality
}

\author{
Atanu Ghoshray ${ }^{1} \cdot$ Issam Malki ${ }^{2}$. Javier Ordóñez ${ }^{3}$ \\ Received: 26 October 2018 / Accepted: 9 March 2021 / Published online: 7 April 2021 \\ (c) The Author(s) 2021
}

\begin{abstract}
We analyse top income and wealth shares data, by conducting a robust estimation of trends, tests for structural breaks, and tests for determining persistence. We include Anglo-Saxon countries, continental Europe and Asian countries, grouped under different percentiles and deciles, spanning a period that is at least close to a century. We find that the top income shares for almost all countries are characterised by broken trends, or level shifts. The preponderance of trend breaks appears in the 1970s and 1980s where after a negative trend changes in magnitude or direction. Finally, shocks to the top income share data are not transitory, which have consequences for policy such as advocating redistributive measures.
\end{abstract}

Keywords Inequality $\cdot$ Top income shares $\cdot$ Trends $\cdot$ Persistence

JEL Classification $\mathrm{C} 22 \cdot \mathrm{C} 32 \cdot \mathrm{N} 30$

\section{Introduction}

In 1953, Simon Kuznets and Elizabeth Jenks published Shares of Upper Income Groups in Income and Saving, where they produced the first comparable long-run income distribution series. One year later, in his famous presidential address to the American Economic Association, Kuznets first addressed the "character and causes

Issam Malki

i.malki@westminster.ac.uk

Atanu Ghoshray

Atanu.Ghoshray@newcastle.ac.uk

Javier Ordóñez

javier.ordonez@uji.es

1 Newcastle University Business School, Newcastle University, 5 Barrack Road, Newcastle NE1 4SE, UK

2 Westminster Business School, Westminster University, 35 Marylebone Road, London NW1 5LS, UK

3 Universitat Jaume I and Institute of International Economics, 12071 Castellón de la Plana, Spain 
of long-term changes in the personal distribution of income' (Kuznets 1955). In his speech, Kuznets emphasised the need to develop proper definitions of inequality and outlined the properties of the data required for the study of inequality over time. Since then, efforts have been made to provide data on inequality. While the primary focus has been on building micro-panel data sets based on national household surveys, the consequent lack of data spanning a long period meant that the long-run analysis of inequality remained under-researched.

Until recently, existing databases on inequality did not cover a long enough time span. Since structural changes in income and wealth distributions are relatively slow and very often span over several decades, it is important to analyse inequality measures that cover a long enough period (Piketty 2007 p.2), preferably a centurial perspective or closer, in order to properly understand such changes in a broader historical perspective. The much called for building up a long time series data set on inequality was taken up by Piketty (2003) which involved constructing a series of top income shares for France, spanning the entire twentieth century. This led to a growing interest among various researchers in the long-run dynamics of inequality, and similar efforts of constructing data sets spanning long periods for many other countries. The data on top income shares has been employed in many studies to draw attention to the rich and their income levels by uncovering the top income distributions. This approach contributes to the set of studies that have focussed on top income distributions rather than the overall measures of inequality such as the Gini. As pointed out by Roine and Waldenström (2015), top income shares are not just about the rich and, in the absence of available alternatives, they provide a useful general measure of inequality over time, even if they say nothing meaningful about the changes happening within the lower part of the income distribution.

There have been calls for exploiting the dynamics of long-run inequality data over time, paying attention to the variation of countries, using econometric methods to determine whether structural breaks are present in the trend, as well as the underlying signs and magnitudes of trend (or no trend) in the regimes demarcated by the breaks. To our knowledge, Roine and Waldenström (2011) make the first attempt of analysing breaks and trends in the data of top income shares of eighteen countries. Their research aims to identify common breaks and estimate breaking trends among countries and groups of countries, such as Nordic, AngloSaxon, Continental Europe and Asia. While their study is highly insightful, there are two limitations of their study. First, the inequality data is assumed to be stationary in their econometric analysis. We do not find any support for this assumption, rather on the contrary, inequality measures are found to be nonstationary integrated processes; therefore, not accounting for this property of the time series data on inequality can lead to inaccurate trend estimation. To be specific, if the data series is integrated of order one (which implies that the data series would need to be first differenced to achieve stationarity) then standard methods of least squares to estimate and test the significance of the trend will suffer from severe 
size distortions (see Ghoshray et al. 2014). ${ }^{1}$ We choose to employ a range of robust procedures that allow us to be agnostic to the order of integration of the data. Secondly, another drawback is the choice of too many breaks, especially in small samples from 1950 onwards. The maximum number of breaks must be chosen according to the sample size so that sufficient observations are in each sub-sample (Kejriwal and Perron 2010, p. 320). Besides, a unit root process can be viewed as a limiting case of a stationary process with multiple breaks, one that has a break (permanent shock) every period. Sequential procedures for detecting trend breaks will be based on successively smaller data subsamples (as more breaks are allowed) thereby leading to low power and/or size distortions (see Kejriwal and Perron 2010). We select the maximum number of breaks in accordance with the recommendations by Kejriwal and Perron (2010) which have also been followed in empirical studies by Harvey et al. (2013) and Ghoshray et al. (2014).

As these methodological issues are crucial for correctly specified trend estimates and persistence measures, we elaborate on these points. Past studies that have estimated trends had to conduct unit root tests to determine whether the data series can be characterised as trend stationary or difference stationary. This is because Perron (1988) noted that the correct specification of the trend function is important in the context of testing for a unit root in the data. For example, if the data contains a unit root, then the standard method of least squares to test for the presence of a trend would suffer from severe size distortions. Or, if the data is mistakenly considered to contain a unit root when in fact the data is trend stationary, the tests will be inefficient and will lack power relative to the trend stationary process (see Perron and Yabu 2009b). The situation is further complicated if one entertains the possibility of structural breaks in the data series. It is well known that we are likely to under-reject the unit root null if we neglect structural breaks in a trend stationary process (Perron 1989). Alternatively, a neglected trend break in a data series that contains a unit root can lead standard unit root tests to incorrectly suggest the presence of stationarity (Leybourne et al. 1998). While recent studies allow for structural breaks in unit processes, what is not clear at the onset is whether structural breaks are at all present in the data. A problem with the application of these unit root tests is that they provide little information regarding the existence and number of trend breaks as well as whether the breaks are pure level shifts or affect both the level and slope of the trend function. Besides, when testing for a structural break, we have no knowledge of the order of integration of the data. Inference based on a test for structural breaks on the data series depends on whether a unit root is present, while tests based on differenced data can have very poor properties when the series contains a stationary component (Vogelsang 1998). This circular testing problem makes it imperative to employ robust procedures that allow us to be agnostic to the form of serial correlation in

\footnotetext{
1 Roine and Waldenstrom (2011) apply methods due to Bai and Perron (2003) and Qu and Perron (2007) that require the data to be trend stationary and our subsequent tests find to the contrary, that the data is integrated of order one.
} 
the data. Accordingly, we adopt robust procedures to estimate trend breaks (e.g., the procedure due to Perron and Yabu (2009a; Kejriwal and Perron 2010; Harvey et al. 2009), as well as pure level breaks (due to Harvey et al. 2010), and trend estimates (due to Perron and Yabu 2009b).

Besides estimating structural breaks and breaking trends, we examine whether shocks to top income shares are persistent or not. To the best of our knowledge, this has not been explicitly investigated in past studies, and we thereby make a contribution to the literature.. We motivate our use of methods by taking an intuitive approach, by determining if structural breaks are at all present in the data before proceeding to conduct unit root tests that allow for such breaks. The reason is that standard tests suffer from low power due to the inclusion of extraneous break dummies. This leads to the possible estimation of a differenced specification when a level specification may be more appropriate. Campbell and Perron (1991) argue that the proper specification of the deterministic components is essential to obtaining unit root tests with reliable finite sample properties. Secondly, the standard unit root tests suffer from serious power and size distortions when structural breaks are included only under the null or only under the alternative hypotheses (see Ghoshray et al. 2014). Given that we find overwhelming evidence in favour of structural breaks in the data, we apply a set of unit root tests that allows for breaks in the level and the slope under both the null and alternative hypotheses developed by Carrion-i-Silvestre et al. (2009). Such a symmetric treatment of breaks alleviates the size and power problems that affect most of the standard structural break unit root tests, such as the tests due to Zivot and Andrews (1992), and Lumsdaine and Papell (1997). For the single case where we find no instability either in the level or in the slope, we apply standard (no break) unit root tests developed by Elliott et al. (1996) and Ng and Perron (2001).

This paper provides a comprehensive univariate time series analysis of top income and wealth shares data. This involves a robust estimation of trends, tests for structural breaks, and determining persistence in top income and wealth shares for twelve countries, which include Anglo-Saxon countries, continental Europe and Asian countries. We choose data that spans a period that is at least close to a century to allow for the potential presence of structural breaks. The measures of inequality include top income and wealth shares. We analyse the top $0.1 \%, 1 \%$ and $10 \%$ of the income distribution, and the top $1 \%$ and $10 \%$ of the wealth distribution. The analysis of breaks, trends, and persistence in the data is carried out separately for each individual time series. We make an empirical contribution to the literature by addressing the dynamics of inequality of income and wealth over time using suitable and robust econometric procedures. Accordingly, we set out the following set of hypotheses to be tested:

Hypothesis I Do top income/wealth share data exhibit broken trends? Here we want to determine whether we can detect structural breaks at what has been observed in past studies as turning points, that allow us to demarcate two or three regimes: prior to Great Depression or World War II, following from this point of time up to the 1980s; and then the period thereafter. 
Hypothesis II Is their evidence of top income/wealth shares following a U-shape or L-shape trend? In other words, whether the trend of top income shares was high prior to the Great Depression, then decrease between World War II and the mid1970s, and since then increase again or flatten out (Atkinson et al. 2011). These regimes may coincide with the start of assembly lines (early part of the twentieth century) the high rates of marginal taxation from post war period to the late 1970s, followed by the drastic cuts to the top rates of taxes, a surge in incomes, as well as deregulation of the financial sector.

Hypothesis III Allowing for these structural changes if they exist, do we find evidence of persistent inequality? If shocks to inequality are not transitory, then exogenous shocks, such as technological innovations or financial shocks, are likely to have persistent effects, which have consequences for policy such as advocating redistributive measures (Christopoulos and McAdam 2017). Alternatively, if shocks to inequality are transitory, then it implies that opportunities exist for distributional mobility that allow income shares to be brought towards a constant level in the long run (Islam and Madsen; 2015). It has been argued that since the 1980s, inequality has been extreme and persistent. Is there an argument that countries which never were directly involved in the war have not been inclined to impose a post-war Egalitarian regime? Is it the case that as a result, the top income shares have been persistent?

To answer these questions, we make use of methods that are robust and allow us to be agnostic of the underlying order of integration of the data. These robust methods, to our knowledge, have not been applied to top income share data. In our analysis, we provide confidence intervals to determine whether the trends are significant. To this end, we first check to see whether there are trend breaks, in which case the trend estimation is broken which leads to either the magnitude and/or the sign of the trend to change with time. The contribution is therefore empirical, as we are providing robust estimations of trend and persistence in the top income and wealth shares data.

The rest of the paper is organised as follows. Section 2 provides a review of the literature. Section 3 explains the econometric methodology used to test these hypotheses. Section 4 reports the empirical results. The final section concludes.

\section{Literature review}

Piketty (2003) documents that for France, inequality increased from the beginning of the twentieth century to World War I, after which it decreased until the late 1970s, and then the trend started to rise again. This study has proven to be highly influential, prompting a range of studies investigating the trends in top income shares in other countries such as UK (Atkinson 2005), USA (Piketty and Saez 2003), Canada (Saez and Veall 2005), continental Europe and the developed countries (Atkinson and Piketty 2007), Australia (Atkinson and Leigh 2007), Japan (Moriguchi and Saez 2010) and India (Chancel and Piketty 2019). In general, the studies find that the 
measures of inequality have differing trends depending on the period of time and the associated underlying economic conditions. For example, the causes for decline in top income shares over the first half of the twentieth century have been attributed to the loss of large amounts of wealth to capital owners caused by exogenous shocks, thereby decreasing their income share (Roine et al. 2009). This decline in wealth continued to fall decades after World War II due to high taxes. However, after 1980 it has been argued that that top income shares have increased in AngloSaxon countries but not in Continental European countries (Roine et al. 2009), and this has not been due to increases in capital incomes but rather due to increased wage inequality (Piketty et al. 2014). For example, Piketty et al. (2014) argue that when top rates of taxes were cut, this may have led to chief executives negotiating harder for higher remuneration and bonuses. Atkinson and Piketty (2007) argue that the top 1\% income shares in European and English-speaking countries maintained a relatively high level up until World War I. This was followed by a drop that took place during World War II and the Great Depression, although the fall in top income shares was more gradual for those countries that stayed out of World War II. From then on, the top income share declined steadily over the twentieth century up until around 1980, when it began to increase again. According to Atkinson et al. (2011), Anglo-Saxon countries (such as Australia, New Zealand, USA) have experienced a substantially greater increase than non-English speaking countries (such as France, Sweden, Norway, Finland, Netherlands).

Despite the strong emphasis in the top income share literature on the diverging patterns between Anglo-Saxon countries and continental Europe, recent studies covering many other countries have provided deeper insights into the long-run evolution of inequality. Atkinson and Piketty (2010) and Atkinson et al. (2011) provide evidence on inequality trends across six different groups of countries, namely AngloSaxon, continental Europe, Nordic, Asian, African and Latin American countries. According to Roine and Waldenström (2015), almost all countries, which include Nordic, Anglo Saxon and Asian, exhibit a secular decline in top income shares over the twentieth century. These recent studies conclude that divergences within country groups appear from around the 1980s onwards, with substantial increases for the Western English-speaking countries as well as China and India; a modest increase in some Nordic countries and Southern European countries; and no increase or decrease in some Continental European countries and Japan. These results suggest that Kuznet's proposal that inequality follows an inverted U-shape ${ }^{2}$ does not apply to all countries.

The literature on inequality has proposed several theories aimed at explaining the trends and structural breaks present in inequality data over the last century. For example, Murphy (1999) and Krueger (2012) suggest skill-biased technological

\footnotetext{
2 In this paper, we refer to the following shapes as suggested by Atkinson et al. (2011) which we define by structural breaks and corresponding regimes. For example, (1) a U-shape refers to a process characterised by two structural breaks, and therefore three regimes starting with a negative trend, then zero trend and positive trend; (2) an L-shape characterised by a single break and two regimes with a negative trend followed by a zero trend. We further allow for a (3) V-shape which refers to a process characterised by one structural break, and therefore two regimes comprising a negative trend followed by a positive trend.
} 
change as one of the main factors. According to the proponents of this theory, in the absence of a growing supply of skilled workers, technological change will increase the wage difference between skilled and unskilled workers. However, Atkinson (2008) argues that if countries are affected by the same technological change, the impact on wages will depend on the ability of each country to supply workers with higher skills, and therefore, skill-biased technological change does not automatically lead to wage differences and higher inequality. Further, Caselli (1999) points out that not all technological changes are in fact skill-biased. Instead, some technological changes may have boosted the productivity of low-skilled workers (Mokyr 1990). Roine et al. (2009) mention the role that political climate can play on inequality. Distinctions are drawn between Anglo-Saxon countries which tend to be liberal welfare states, as opposed to continental European countries that are corporatist-conservative, which is again in contrast with Scandinavian countries which are social democratic welfare states. Also, as an example, top income shares in the USA and UK increased due to the tax breaks offered by Reagan and Thatcher implying political regimes can matter. Piketty (2003) devotes space in his study about the role of progressive taxation on the evolving dynamics of top income shares in the case of France. The role of tax progressivity is also analysed by Roine and Waldenström (2008) in the case of Sweden. Saez and Veall (2005) analyse the drop of marginal rates of taxation in the 1960s on Canada. They conclude that the increase in top income shares for Canada is more to do with the similar factors affecting the USA, rather than tax progressivity. For Canada, two studies by Saez and Veall (2005, 2007) conclude the top income shares surged in the last two decades of the twentieth century, and further evidence was found by Murphy et al. (2007) and Veall (2010). In another study, examining the estimates from a new set of taxfiler data, Veall (2012) notices that the rapid increase in top income shares in Canada was not smooth after 2000, rather variations were noted. Jäntti et al. (2010) conclude that the increase in top income shares in Finland has been a result of lowering the progressivity of income tax. It can be noted in the study by Chancel and Piketty (2019) that the increase in top income shares of India coincide with the decrease of top rates of income tax from 62 to $50 \%$ in the early 1980s. Regarding the role of globalisation in explaining inequality, the findings in the literature are polarised. While some authors conclude that globalisation accentuates inequality (Firebaugh 2003; Wade 2004), others suggest that economic integration has played an important role in closing the inequality gap (Dollar and Kraay 2002). Globalisation, along with information technology, may also play an important role in explaining the increasing wage dispersion observed for "stars" in certain professions (Rosen 1981). The link between inequality and growth has been studied in both the theoretical and the empirical literature, with conflicting results. Growth in per capita GDP has been associated with increases in top income shares (Roine et al. 2009).

While there has been a continuously evolving discussion of the time-varying nature of inequality for various developed countries, the econometric analysis is limited. This may be due to the fact that the income distribution data is relatively new (Atkinson and Leigh 2013). One of the few econometric applications on time series data pertaining to inequality is that of Roine and Waldenström (2011), where they apply multiple structural change tests within a single equation framework as 
proposed by Bai and Perron $(1998,2003)$, and a system of equations framework following the recent methodology developed by Qu and Perron (2007). The empirical analysis of Roine and Waldenström (2011) attempts to test for and identify common breaks in the data of top income shares of eighteen countries using two separate time series data sets; one that covers a sample spanning almost a century and another that focusses on the post war period. As discussed earlier, the drawback is that their study assumes the top income share data to be stationary, and the choice of too many breaks in a small data sample. These issues lead to misspecified results as explained in the previous section.

Besides income inequality, research in to wealth inequality has been gaining importance especially since publication of the book Capital in the Twenty First Century by Piketty (2014) where the main driver of inequality has been the tendency of capital returns to exceed the rate of economic growth. Kopczuk (2015) uses survey based and estate tax methods to conclude that top $1 \%$ wealth share of the USA increased at a modest rate. Saez and Zucman (2016) estimate wealth inequality using capitalisation methods and find that the top $1 \%$ and top $10 \%$ wealth shares were high in the USA in the early part of the twentieth century and then have been decreasing up to the late 1970s before increasing again. Alvaredo et al. (2018) find that the top wealth shares for the UK were relatively constant from 1895 to 1914, and then have decreased sharply until 1979. Since then, the wealth shares have started to rise. In a more recent study, Zucman (2019) notes that the top shares of wealth inequality for France and UK show a similar path which may be due to nationalisations, rent controls and taxation during the 1950s to the 1970s. In recent decades, Zucman (2019) notes that the wealth inequality for France and the UK has been rising at a slower rate than the USA. He notes that the wealth inequality for both top $1 \%$ and top $10 \%$ is close to what they were a century ago, whereas for France and UK the wealth inequality levels are still much lower than what they were in the early 1900s. While these seminal studies have made a significant contribution by developing methods to construct the time series of top wealth shares, the commentary of the trends of these inequality measures is based on visual inspection and not robust econometric methods.

A recent study by Islam and Madsen (2015) tests whether income inequality is persistent by employing a long panel data set of Gini coefficients and top 10\% income shares for 21 OECD countries over the period 1870-2011. They employ the individual and panel stationary tests due to Carrion-i-Silvestre et al. (2005) allowing for a maximum of five structural breaks. The test is based on the Kwiatkowski et al. (1992) (KPSS) test. They compute the bootstrap distribution following Maddala and $\mathrm{Wu}(1999)$ with 10,000 replications to take account of cross-sectional dependence in the estimates of the KPSS test statistics, in order to reduce the bias and increase the power of the tests. As a robustness test, they employ the Bai and Carrion-i-Silvestre (2009) panel unit root tests that allow for multiple structural breaks. Their study concludes that the shocks to income inequality are temporary. The methods applied are comprehensive and show that there are mechanisms that bring income shares to a constant level. However, in another more recent and comparable study, Christopoulos and McAdam (2017) examine inequality persistence in a multi-country unbalanced panel using a range of stationary and long memory tests. They analyse 
the Gini index for 47 countries spanning a time period of at least 30 years. The tests employed include panel unit roots with and without breaks. The test for unit roots with breaks is based on a novel procedure that allows for a Fourier function. Finally a panel fractional unit root test is also conducted. Conducting these tests, they find no evidence of shocks being transitory to inequality measures. The results of Christopoulos and McAdam (2017) contradict those of Islam and Madsen (2015).

\section{Econometric methodology}

As described earlier, the circular testing problem underscores the need to employ break testing procedures that do not require knowledge of the form of serial correlation in the data. Based on those arguments, we choose to estimate the trend function based on the general model given by:

$$
\begin{aligned}
& y_{t}=\mu_{0}+\beta_{0} t+\sum_{i=1}^{K} \mu_{i} D U_{i t}+\sum_{i=1}^{K} \beta_{i} D T_{i t}+u_{t}, \quad t=1,2, \ldots, T \\
& u_{t}=\rho u_{t-1}+\varepsilon_{t}, \quad t=2,3, \ldots, T, \quad u_{1}=\varepsilon_{1}
\end{aligned}
$$

where $y_{t}$ denotes the data on top income shares, $D U_{i t}=I\left(t>T_{i}\right)$, $D T_{i t}=\left(t-T_{i}\right) I\left(t>T_{i}\right), \quad i=1,2, \ldots, K . \quad$ A break in the trend occurs at time, $T_{i}=\left[T \lambda_{i}\right]$, where $\beta_{i} \neq 0$, and $\lambda_{i}$ is the break fraction. The date(s) for any $\operatorname{break}(\mathrm{s})$ in the series and the number of breaks $(K)$ are unknown. No assumptions are made with regard to the nature of the error term, i.e. $u_{t}$ can be either $I(0)$, that is, $|\rho|<1$, or $I(1)$ that is, $\rho=1$. To determine whether structural breaks exist, we test the null hypothesis $H_{0}: \beta_{i}=0$ against the alternative $H_{1}: \beta_{i} \neq 0$. Perron and Yabu (2009a) propose a robust method to detect a break in the trend function based on a Feasible Quasi Generalized Least Squares (FGLS) method and a further second break using a sequential approach due to Kejriwal and Perron (2010).

We first test for a single structural break in the slope of the trend function using the robust procedure of Perron and Yabu (2009a). A rejection of null hypothesis of no break by this robust test is evidence in favour of a break, whereupon we then proceed to test for one against two slope breaks using the sequential approach of Kejriwal and Perron (2010). Again, this latter test allows us to distinguish between one and two breaks while being agnostic to whether a unit root is present. Given the number of sample observations available to be approximately 100 , we allow for a maximum of two breaks in our empirical analysis. There are two reasons for this. As we have explained earlier, we expect according to the observations made by Atkinson et al. (2011) that there may be two breaks to account for the U-shape trend in top income shares data. Secondly, as discussed earlier, from an econometric viewpoint allowing for a large number of breaks is not an appropriate strategy (see Harvey et al. 2013; Ghoshray et al. 2014).

To briefly describe the Perron and Yabu (2009a) procedure, the following autoregression on the error term in (1) is estimated: 


$$
\widehat{u}_{t}=\alpha \widehat{u}_{t-1}+\sum_{i=1}^{k} \varphi_{i} \widehat{u}_{t-i}+e_{t k}
$$

where the lag length $k$ is chosen using the Bayesian Information Criteria (BIC). The estimate of $\alpha$ is obtained using OLS, denoted $\tilde{\alpha}$. Perron and Yabu (2009a) use a bias corrected version of $\tilde{\alpha}$, denoted by $\tilde{\alpha}_{M}$, to improve the finite sample properties of the tests, proposed by Roy and Fuller (2001). In the next step, Perron and Yabu (2009a) calculate the super-efficient estimator of $\alpha$ given by:

$$
\tilde{\alpha}_{M S}= \begin{cases}\tilde{\alpha}_{M} & \text { if }\left|\tilde{\alpha}_{M}-1\right|>T^{-1 / 2} \\ 1 & \text { if }\left|\tilde{\alpha}_{M}-1\right| \leq T^{-1 / 2}\end{cases}
$$

Using a super-efficient estimate is crucial for obtaining nearly identical limit properties in the $\mathrm{I}(0)$ and $\mathrm{I}(1)$ cases. The estimate $\tilde{\alpha}_{M S}$ is then used to construct the quasi-differenced regression:

$$
\begin{aligned}
\left(1-\tilde{\alpha}_{M S}\right) y_{t} & =\left(1-\tilde{\alpha}_{M S}\right) x_{L 1, t}^{\prime} \Psi+\left(1-\tilde{\alpha}_{M S}\right) u_{t} ; t=2,3, \ldots, T \\
y_{t} & =x_{L 1,1}^{\prime} \Psi+u_{1}
\end{aligned}
$$

where $\Psi=\left(\mu_{0}, \beta_{0}, \mu_{1}, \beta_{1}\right)^{\prime}$. The resulting estimates from the regression are denoted as.

$\tilde{\Psi}^{F G}=\left(\tilde{\mu}_{0}^{F G}, \tilde{\beta}_{0}^{F G}, \tilde{\mu}_{1}^{F G}, \tilde{\beta}_{1}^{F G}\right)^{\prime}$. The Wald test $W_{Q F}(\lambda)$ for a particular break function $\lambda_{1}$, where the subscript $Q F$ denotes the 'Quasi-Feasible', is given by:

$$
W_{Q F}\left(\lambda_{1}\right)=\left(\tilde{\beta}_{1}^{F G}\left(\lambda_{1}\right)\right)^{2} / \sqrt{ }\left[\left(\tilde{h}_{v}\left(\lambda_{1}\right)\right)\left\{\left(X^{\alpha \prime} X^{\alpha}\right)^{-1}\right\}\right]
$$

where $X^{\alpha}=\left[x_{L 1,1},\left(1-\tilde{\alpha}_{M S}\right) x_{L 1,2}, \ldots .,\left(1-\tilde{\alpha}_{M S}\right) x_{L 1, T}\right]^{\prime}$. The quantity $\tilde{h}_{v}\left(\lambda_{1}\right)$ is an estimate of $2 \pi$ times the spectral density function of $v_{t}=(1-\alpha L) u_{t}$ at frequency zero. If $\left|\tilde{\alpha}_{M S}\right|<1$, a kernel-based estimator given by

$$
\tilde{h}\left(\lambda_{1}\right)=T^{-1} \sum_{t=1}^{T} \widehat{v}_{t}^{2}\left(\lambda_{1}\right)+2 T^{-1} \sum_{j=1}^{T-1} k(j, \tilde{l}) \sum_{t=j+1}^{T} \widehat{v}_{t}\left(\lambda_{1}\right) \widehat{v}_{t-j}\left(\lambda_{1}\right)
$$

is employed where $\hat{v}_{t}\left(\lambda_{1}\right)$ are the least squares residuals from (3). The function $k(j, \tilde{l})$ is the quadratic spectral kernel and $\tilde{l}$ is the bandwidth. When $\tilde{\alpha}_{M S}=1$, the estimate suggested is an autoregressive spectral density estimate that can be obtained from the regression:

$$
\widehat{v}_{t}=\sum_{i=1}^{k} \xi_{i} \hat{v}_{t-i}+e_{t k}
$$

where the lag length $k$ is again chosen using the BIC. Following Andrews (1993) and Andrews and Ploberger (1994), Perron and Yabu (2009a) consider the Mean, Exp, and sup functionals of the Wald test for different break dates. They found that with the Exp functional, the limit distribution in the $\mathrm{I}(0)$ and $\mathrm{I}(1)$ cases is nearly identical. They recommend the following statistic to determine the structural break: 


$$
\operatorname{Exp} W=\ln \left[T^{-1} \sum_{\lambda_{1} \in \Lambda_{1}} \exp \left(1 / 2 W_{Q F}\left(\lambda_{1}\right)\right)\right]
$$

A further robust test to detect structural breaks due to Harvey et al. (2009) is applied. This is a $t_{\lambda}$ statistic which allows us to test for a structural break allowing us to be agnostic to the underlying order of integration of the data. The statistic is constructed as a weighted average of the regression t-statistic for a broken trend from a regression in levels and in first differences (see Harvey et al. 2009) for details. The statistic is given by:

$$
t_{\lambda}=\left[\lambda\left(S_{0}(\hat{\tau}), S_{1}(\tilde{\tau})\right) \times t_{0}^{*}\right]+\phi_{\varsigma}\left[\left\{1-\lambda\left(S_{0}(\hat{\tau}), S_{1}(\tilde{\tau})\right)\right\} \times t_{1}^{*}\right]
$$

where $\phi_{\varsigma}$ is a finite constant, $\left(S_{0}(\hat{\tau}), S_{1}(\tilde{\tau})\right) S_{0}(\hat{\tau})$ and $S_{0}(\hat{\tau})$ are auxiliary statistics. As the sample size approaches infinity, the weights $\lambda\left(S_{0}(\hat{\tau}), S_{1}(\tilde{\tau})\right) \rightarrow 1$ when the error term in the trend function is $\mathrm{I}(0)$, and $\rightarrow 0$, when $\mathrm{I}(1)$.

In the spirit of Perron and Yabu (2009a), Kejriwal and Perron (2010) propose a sequential procedure that allows one to obtain a consistent estimate of the true number of breaks irrespective of whether the errors are $\mathrm{I}(1)$ or $\mathrm{I}(0)$. The first step is to conduct a test for no break versus one break. Conditional on a rejection, the estimated break date is obtained by a global minimisation of the sum of squared residuals. The strategy proceeds by testing each of the two segments (obtained using the estimated partition) for the presence of an additional break and assessing whether the maximum of the tests is significant. Formally, the test of one versus two breaks is expressed as:

$$
\operatorname{Exp} W(2 \mid 1)=\max _{1 \leq i \leq 2}\left\{\operatorname{Exp} W^{(i)}\right\}
$$

where $\operatorname{Exp} W^{(i)}$ is the one break test in segment $i$. We conclude in favour of a model with two breaks if $\operatorname{Exp} W(2 \mid 1)$ is sufficiently large.

We make a further test for pure level shifts due to Harvey et al. (2010) that allows us to be agnostic of the order of integration of the data series. Conditional on the presence of a stable slope (that is, setting $\beta_{i}=0$ in (1)) we set up the null hypothesis $H_{0}: \mu_{i}=0$ against the alternative $H_{1}: \mu_{i} \neq 0$. Specifically, we consider the union of rejections based on a decision rule as follows:

$$
U: \text { Reject } H_{0} \text { if }\left\{S_{1}>\varphi_{\varepsilon} c v_{\varepsilon}^{1} o r S_{0}>\varphi_{\varepsilon} c v_{\varepsilon}^{0}\right\}
$$

where $c v_{\varepsilon}^{1}$ and $c v_{\varepsilon}^{0}$ denote the $\varepsilon$ significance level asymptotic critical values of $S_{1}$ under I(1) errors and $S_{0}$ under I(0) errors, respectively; and $\varphi_{\varepsilon}$ is a positive scaling constant. The statistics $S_{1}$ and $S_{1}$ are constructed using the long-run variances from I(1) and I(0) errors, respectively (see Harvey et al. 2010).

In the second stage of the empirical analysis, we conduct robust estimations of the trend. If no structural breaks in the trend are found to be present in the data, then we estimate the trend function for the entire sample. In the cases where we obtain pure level breaks holding the trend constant, the significance of the trend is determined using the first difference specification if a unit root is present in 
the data; otherwise, a level specification is used if there is no unit root. However, if trend breaks are found to be present in the data, we delineate the sub-samples from the break points and conduct robust trend estimation for each of the regimes demarcated by the break points. To this end, we apply an appropriate econometric method of robust trend estimation due to Perron and Yabu (2009b) that allows one to be agnostic to the nature of persistence of errors in the trend function.

Following this procedure, the residuals $\widehat{u}_{t}$ in (2) are obtained from a regression of $y_{t}$ on $x_{t}=(1, t)^{\prime}$. The super-efficient estimate $\tilde{\alpha}_{M S}$ (obtained as discussed earlier) is used to estimate the quasi-differenced regression

$$
\begin{aligned}
\left(1-\tilde{\alpha}_{M S} L\right) y_{t} & =\left(1-\tilde{\alpha}_{M S} L\right) x_{t}^{\prime} \Psi^{0}+\left(1-\tilde{\alpha}_{M S} L\right) u_{t} ; t=2,3, \ldots, T \\
y_{t} & =x_{1}^{\prime} \Psi+u_{1}
\end{aligned}
$$

where $\Psi^{0}=\left(\mu_{0}, \beta_{0}\right)^{\prime}$. We denote the estimate of $\beta_{0}$ from this regression by $\hat{\beta}_{0}$. Then, using the notation $x^{F G}=\left(x_{1}^{F G}, x_{2}^{F G}, \ldots, x_{T}^{F G}\right)^{\prime}$ with $x_{1}^{F G}=(1,1)^{\prime}$; $x_{t}^{F G}=\left[1-\tilde{\alpha}_{M S}, t-\tilde{\alpha}_{M S}(t-1)\right]$ for $t=2,3, \ldots, T$, a $100(1-\alpha) \%$ confidence interval for $\beta_{0}$; again valid for both $\mathrm{I}(1)$ and $\mathrm{I}(0)$ errors, is obtained as

$$
\widehat{\beta}_{0} \pm c_{\alpha / 2} \sqrt{\left(\tilde{h}_{v}\right)\left\{\left(X^{\alpha \prime} X^{\alpha}\right)^{-1}\right\}}
$$

where $c_{\alpha / 2}$ is such that $P\left(x>c_{\alpha / 2}\right)=\alpha / 2$ for $x \sim N(0,1)$ and $\tilde{h}_{v}$ is already defined.

In the final stage of empirical analysis, we conduct unit root tests to determine whether shocks to the top income and wealth shares data are transitory or not. If there is evidence of structural breaks, we apply a class of unit root tests which allows for breaks under both the null and alternative hypotheses (Carrion-i-Silvestre et al. 2009). The tests are extensions of the feasible point optimal statistic of Elliott et al. (1996) and the $M$ class of tests due to $\mathrm{Ng}$ and Perron (2001).

Consider Eq. (1); the estimates of the break fractions $\lambda_{i}$ and the regression parameters are obtained by minimising the sum of squared residuals from the quasi-differenced regression analogous to (4). The sum of squared residuals evaluated at these estimates is denoted by $S(\alpha(\hat{\lambda}), \hat{\lambda})$, where $\alpha(\hat{\lambda})=1-c(\hat{\lambda}) / T$. The feasible point optimal statistic calculated by Carrion-i-Silvestre et al. (2009) is then given by:

$$
P_{T}=S(\alpha(\hat{\lambda}), \hat{\lambda})-\alpha(\hat{\lambda}) S(1, \hat{\lambda}) / s^{2}(\hat{\lambda})
$$

where $s^{2}(\hat{\lambda})=s_{e k}^{2} /[1-b(1)]^{2}$ and $s_{e k}^{2}=(T-k)^{-1} \sum_{t=k+1}^{T} \hat{e}_{t k}^{2} ; b(1)=\sum_{j=1}^{k} \widehat{b}_{j}$. Both $\widehat{b}_{j}$ and $\hat{e}_{t k}^{2}$ are obtained using OLS estimation of the following equation:

$$
\Delta \tilde{y}_{t}=b_{0} \tilde{y}_{t-1}+\sum_{j=1}^{k} b_{j} \Delta \tilde{y}_{t-j}+e_{t k}
$$

where $\tilde{y}_{t}=y_{t}-\hat{\Psi}_{2}{ }^{\prime} x_{L i, t}(\hat{\lambda}) ; \quad x_{L i, t}(\hat{\lambda})=\left[1, t, D U_{i t}(\hat{\lambda}), D T_{i t}(\hat{\lambda})\right] ; i$ denotes the number of breaks; and $\widehat{\Psi}_{2}^{\prime}$ is the OLS estimate of the quasi differenced regression (4). 
Carrion-i-Silvestre et al. (2009) also consider extensions of the $M$-class of tests developed by $\mathrm{Ng}$ and Perron (2001). These extensions involve the inclusion of multiple structural breaks, building on the work of Perron and Rodriguez (2003). The statistics computed by Carrion-i-Silvestre et al. (2009) are similar to $\mathrm{Ng}$ and Perron (2001) where the null hypothesis is that of a unit root against the alternative of stationarity with the symmetric treatment of structural breaks in the null and alternative hypothesis. These statistics are computed as follows:

$$
\begin{gathered}
M P T=\left[c^{2}(\hat{\lambda}) T^{-2} \sum_{t=2}^{T} \tilde{y}_{t-1}^{2}+(1-c(\hat{\lambda})) T^{-1} \tilde{y}_{T}^{2}\right] / s^{2}(\hat{\lambda}) \\
M Z a=\left[T^{-1} \tilde{y}_{T}^{2}-s^{2}(\lambda)\right]\left(2 T^{-1} \sum_{t=2}^{T} \tilde{y}_{t-1}^{2}\right)^{-1} \\
M S B=\left(T^{-2} \sum_{t=2}^{T} \tilde{y}_{t-1}^{2}\right)^{1 / 2} / s^{2}(\hat{\lambda}) \\
M Z t=\left[T^{-1} \tilde{y}_{T}^{2}-s^{2}(\lambda)\right]\left(4 s^{2}(\hat{\lambda}) T^{-2} \sum_{t=2}^{T} \tilde{y}_{t-1}^{2}\right)^{-1 / 2}
\end{gathered}
$$

where $s^{2}(\hat{\lambda}), \tilde{y}_{t}$ and $c(\hat{\lambda})$ have already been defined. The computation of the critical values of these powerful unit root tests is described by Carrion-i-Silvestre et al. (2009).

Such a symmetric treatment of breaks alleviates these unit root tests from size and power problems that plague tests based on search procedures (for instance, Zivot and Andrews 1992; Lumsdaine and Papell 1997). If no evidence is found for structural breaks, we apply standard (no break) unit root tests developed by Elliott et al. (1996) and $\mathrm{Ng}$ and Perron (2001). There is always a potential power issue associated with unit root tests allowing for multiple breaks, given that a unit root process is observationally equivalent to a stationary process with multiple breaks in the limit. Simulation evidence presented in Carrion-i-Silvestre et al. (2009) shows that the tests allowing up to two breaks have decent finite sample power when the data generating process is driven by one or two breaks. Indeed, they have much better properties than unit root tests based on search procedures given that they exploit information regarding the presence of breaks.

\section{Data and empirical results}

To conduct the robust econometric procedures, it is imperative that we analyse data sets that are continuously available over a long period of time. We only employ data that covers a time period that is at least close to a century. In an effort to analyse as many countries as possible, we make use of time series data on top income shares from various sources. Data on the top $0.1 \%$ income shares for Australia, Canada, USA, Japan, and France are obtained from Bengtsson and Waldenström (2018) and 
Table 1 Data description

\begin{tabular}{|c|c|c|}
\hline Countries & Data period & Source \\
\hline \multicolumn{3}{|c|}{ Top $0.1 \%$ income share } \\
\hline Australia & $1921-2010$ & Bengtsson and Waldenström (2018) \\
\hline Canada & 1920-2010 & Bengtsson and Waldenström (2018) \\
\hline USA & 1913-2012 & Bengtsson and Waldenström (2018) \\
\hline Japan & 1886-2010 & Bengtsson and Waldenström (2018) \\
\hline India & 1922-2014 & Chancel and Piketty (2019) \\
\hline France & 1915-2013 & Bengtsson and Waldenström (2018) \\
\hline \multicolumn{3}{|c|}{ Top $1 \%$ income share } \\
\hline Australia & 1919-2016 & World Income Database \\
\hline Canada & 1920-2010 & World Income Database \\
\hline New Zealand & 1921-2016 & World Income Database \\
\hline USA & 1913-2014 & World Income Database \\
\hline Japan & 1886-2010 & World Income Database \\
\hline India & 1922-2015 & World Income Database \\
\hline France & 1915-2017 & World Income Database \\
\hline Sweden & 1920-2004 & Waldenstrom webpage \\
\hline Norway & 1920-2004 & Waldenstrom webpage \\
\hline Finland & 1920-2004 & Waldenstrom webpage \\
\hline Netherlands & 1920-2004 & Waldenstrom webpage \\
\hline \multicolumn{3}{|c|}{ Top $10 \%$ income share } \\
\hline USA & 1913-2014 & World Income Database \\
\hline France & 1915-2017 & World Income Database \\
\hline \multicolumn{3}{|c|}{ Top $1 \%$ wealth share } \\
\hline USA & 1913-2014 & World Income Database \\
\hline France & 1902-2014 & World Income Database \\
\hline UK & 1895-2003 & Alvaredo et al. (2018) \\
\hline \multicolumn{3}{|c|}{ Top $10 \%$ wealth share } \\
\hline USA & 1913-2014 & World Income Database \\
\hline France & 1902-2014 & World Income Database \\
\hline UK & $1895-2003$ & Alvaredo et al. (2018) \\
\hline
\end{tabular}

for India from Chancel and Piketty (2019). The top 1\% income shares for Australia, Canada, New Zealand, USA, Japan, India and France are from the World Income Database (WID) and for Sweden, Norway, Finland and Netherlands we use the data made available by Daniel Waldenstrom. ${ }^{3}$ Since the focus is to exploit the maximum length of data that is available, we analyse data sets that cover different lengths of time. For the top $10 \%$ income shares as well as the top $1 \%$ and $10 \%$ wealth shares for USA and France we obtain data from the WID. In all these categories long time

\footnotetext{
3 see: http://www.uueconomics.se/danielw/Data.htm. We thank Prof. Waldenstrom for sharing the data.
} 
(near a century long) series data is only available for USA and France. We found top $1 \%$ and $10 \%$ wealth share data for the UK from Alvaredo et al. (2018). ${ }^{4}$ A brief summary of the time span and source of all the data used in this study is shown in Table 1.

The top income shares data used by Roine and Waldenström (2011) is the personal income tax returns on the national level. Income shares are calculated following a methodology first outlined in Piketty (2003) which builds on the work by Kuznets and Jenks (1953). Top income shares are constructed by dividing the number of top share tax units and their incomes, with the reference tax population and their total income. The income is gross total income before taxes and transfers (see Roine and Waldenström 2011 for details). ${ }^{5}$

Further, the WID puts forward a disclaimer that their methods to generate the top income and wealth share data are likely to be imperfect, and subject to revision. This is based on an ongoing process where researchers affiliated to the WID combine available fiscal, survey and national accounts data. The methods over time have become more systematic, but as they acknowledge, this is still work in progress. It has been noted in studies by Burkhauser et al. (2012), Bricker et al. (2016), that different results in terms of magnitude of changes can be obtained using data from tax records as opposed to data from surveys. Problems with the data from surveys as highlighted by Burkhauser et al. (2012) are that there are problems with the coverage of the survey, sampling issues, and under-reporting. Besides, the information collected from survey units might not capture the responses accurately, or in other words there arises a measurement or processing error (Bricker et al. 2016). Also, there is the problem with fiscal manipulation as highlighted by Burkhauser et al. (2012) where high-income earners are able to adjust their incomes in a way so that they pay less tax. While Piketty and Saez (2003) state this is not a problem when testing long-term trends, it is still not free from criticism of the extent to which income is reported and can still lead to inaccurate measurements of inequality. Accordingly, the WID and other researchers attempt to compute top income shares series using income tax data, national accounts, and Pareto interpolation techniques to estimate the share of total income going to top income and wealth groups. While these techniques are not fully homogeneous over time and across countries, this is the only data available to analyse long-run trends in top income and wealth shares. For the length of time we consider, we are limited to restricting our attention to the top decile, and top percentile.

Some of the sources as we can see from Table 1 can differ and the measures may differ slightly from each other. However, there should be no issues regarding the analysis we conduct as it is univariate in nature. We are not analysing how the different inequality shares relate to one another, but simply how trends in inequality are

\footnotetext{
4 There were some missing observations which we addressed using linear interpolation.

5 As pointed out by an anonymous referee, some caution needs to be exercised when using the century long data. National accounts for the countries considered in this study only came in to being from the 1950s onwards, which implies that the construction of the top income shares which depends on GDP data is unlikely to be precisely accounted for. We gratefully acknowledge this point.
} 
Table 2 Structural break tests

Slope Breaks

Level Breaks Number and location of breaks

\begin{tabular}{llllll}
$\overline{\boldsymbol{E x p}(0 \mid 1)}$ & $\boldsymbol{E x p}(1 \mid 2)$ & $\boldsymbol{t}_{\lambda}$ & $\boldsymbol{U}$ & $\overline{\# \text { of breaks }}$ & Break date(s) \\
\hline
\end{tabular}

Top $0.1 \%$ income shares

\begin{tabular}{|c|c|c|c|c|c|c|}
\hline Australia & $24.29 * * *$ & 0.43 & $5.88 * * *$ & & 1 & 1986 \\
\hline Canada & $1.67 *$ & $10.30 * * *$ & $3.54 * *$ & & 2 & 1933,1971 \\
\hline USA & $4.58 * *$ & -0.09 & $8.96 * * *$ & & 1 & 1970 \\
\hline Japan & 0.35 & & 1.57 & $0.91 * * *$ & 1 & 1944 \\
\hline India & $1.58 *$ & 1.34 & $3.40 * *$ & & 1 & 1977 \\
\hline France & $1.24 *$ & $4.62 * *$ & $3.48 * *$ & & 2 & 1948,1982 \\
\hline \multicolumn{7}{|c|}{ Top $1 \%$ income shares } \\
\hline Australia & 0.76 & N/A & $3.99 *$ & & 1 & 1973 \\
\hline Canada & 0.70 & N/A & 2.39 & $0.72 * *$ & 1 & 1941 \\
\hline New Zealand & 0.38 & N/A & 2.71 & $0.58 *$ & 1 & 1999 \\
\hline USA & $27.49 * * *$ & -0.14 & $6.02 * * *$ & & 1 & 1973 \\
\hline Japan & -0.11 & N/A & 1.30 & $0.68 * *$ & 1 & 1944 \\
\hline India & 0.54 & N/A & $3.88^{*}$ & & 1 & 1978 \\
\hline France & 0.67 & N/A & 2.29 & $0.60 *$ & 1 & 1945 \\
\hline Sweden & $4.87 * *$ & $20.21 * * *$ & $4.23 * *$ & & 2 & 1971,1983 \\
\hline Norway & $14.73 * * *$ & 0.43 & $5.96 * * *$ & & 1 & 1988 \\
\hline Finland & $2.81 * *$ & $2.61 * *$ & 2.97 & & 2 & 1973,1986 \\
\hline Netherlands & 0.05 & & 1.68 & 0.49 & 0 & \\
\hline \multicolumn{7}{|c|}{ Top $10 \%$ income shares } \\
\hline USA & 0.94 & N/A & 2.19 & $0.94 * * *$ & 1 & 1941 \\
\hline France & 0.37 & N/A & 2.23 & $0.57 *$ & 1 & 1945 \\
\hline \multicolumn{7}{|c|}{ Top $1 \%$ wealth shares } \\
\hline USA & $1.64 *$ & -0.16 & $2.98^{*}$ & & 1 & 1975 \\
\hline France & 0.74 & N/A & 2.43 & $0.66^{*}$ & 1 & 1995 \\
\hline UK & $4.60 * *$ & $90.64 * * *$ & & & 2 & 1950,1986 \\
\hline \multicolumn{7}{|c|}{ Top $10 \%$ wealth shares } \\
\hline USA & 1.12 & N/A & $3.32 * *$ & & 1 & 1982 \\
\hline France & 0.46 & N/A & 2.13 & $0.77 * *$ & 1 & 1967 \\
\hline UK & $16.25^{* * *}$ & $130.48 * * *$ & & & 2 & 1950,1986 \\
\hline
\end{tabular}

*****, and *denote significance at the $1 \%, 5 \%$ and $10 \%$ levels, respectively. The number of breaks is determined by statistical significance of rejecting the null of either no slope break or no level shift

evolving over a long enough period of time. In this study we aim to focus on those countries for which we have data that is close to if not more than a century long. The long time span covered allows for interpretation of some historical developments, in particular whether long-run trends can be fitted to the data, and whether exogenous shocks to the top income shares have had a transitory effect on inequality.

Hypothesis I Do top income/ wealth share data exhibit broken trends? 
We test for the presence of a single structural break using the procedure by Perron and Yabu (2009a) and the sequential procedure of detecting two breaks due to Kejriwal and Perron (2010). The null hypothesis is that the data series does not contain a break against the alternative of a single break (i.e. $\operatorname{Exp}(0 \mid 1)$ ). If we find a single break, we then proceed to test the null hypothesis of a single break against the alternative of two breaks (i.e., $\operatorname{Exp}(1 / 2)$ ). We also apply the robust test of Harvey et al. (2009) which is the $t_{\lambda}$ test. If either of tests does not reject the no break null, we then proceed to test for a pure level shift, based on the $U$ test due to Harvey et al. (2010) where the null hypothesis is of no level breaks. Table 2 reports the test results for both slope breaks and level breaks, and if structural breaks are present, the location of the break (i.e., the break date(s)). The results for the top $0.1 \%, 1 \%$ and $10 \%$ income shares, as well as the top $1 \%$ and $10 \%$ wealth shares, are given in Table 2.

Using a comprehensive set of robust trend break tests, we find for the top 0.1 percentile income shares, there are two trend breaks for Canada and France, whereas we find a single trend break for USA, India and Australia. These results are corroborated by the $t_{\lambda}$ test. We do not find a trend break for Japan, so we apply the level break $U$ test instead, and find evidence of a pure level shift. The location of the break dates is mostly around the 1970s and 1980s. The level shift in the case of Japan occurs at 1944, which is supported by Moriguchi and Saez (2010) where they note that World War II had a significant impact on Japan and attribute the sharp drop in top income shares during World War II and thereafter to redistributive policies.

When considering the top 1 percent income shares, we find six countries to contain at least two trend breaks. Most of the trend break locations are around the 1970s. Level shifts are found for Canada, New Zealand, Japan and France. Except for New Zealand, ${ }^{6}$ the break date locations are in the 1940s. The results for France are supported by Piketty (2005) where he notes that the sharp drop in top income shares is mainly due to the fall in capital incomes as top wage shares did not fall during this period. The shocks due to the Great Depression and wars led to capital owners incurring severe losses. Piketty (2005) goes on to argue that the shocks to top income shares in the 1940s had a permanent effect due to the introduction of income and estate taxes. In the case of India, our estimate of the trend break is at 1977-1978 for both top $0.1 \%$ and top $1 \%$ income shares and this coincides well with the sharp drops in the rates of tax progressivity, where substantial cuts were made to the top rates of marginal taxation which were quite high. This clarifies the visual inspection of the data made by Chancel and Piketty (2019) where they observe the turning point to be 1983-1984. Out of the 25 different combinations of countries and the associated top shares of income and wealth chosen, we find that there are trend breaks in 15 of the data series. Six of these show two significant trend breaks and the remaining nine show a single break. At least one of these trend breaks is around the 1970s or 1980s. The preponderance of trend breaks around this period

\footnotetext{
${ }^{6}$ A caveat to note about the top income share data is the level shift that we find in the case of New Zealand in 1999. By construction, the top income share data can be affected by legislation which occurred for New Zealand when the marginal rate of tax was raised in the year 2000 (Atkinson and Leigh 2007). We thank an anonymous referee for raising this point.
} 
fits in with the argument put forward in various studies that the top marginal rates of taxes were reduced in varying degrees approximately around this period (Alvaredo et al. 2013; Piketty et al. 2014), as well as the surge in top wage incomes (Atkinson et al. 2011). In the case of Norway, the break date coincides with banking crisis of 1988-1992. Note that these break points denote that the underlying trends fitted to the data can be described as broken trends, by which we can divide the data into regimes and estimate the trends for these different regimes, provided there is sufficient data points within each regime. Where trend breaks could not be found, we detect for possible pure level shifts. Out of the remaining 10 data series, we find a pure level shift for 9 of them. Interestingly, out of these 9 possible classifications based on country and income group, we find 6 of them to show a pure level shift in the 1940s. Only the Netherlands does not show any significant trend or level break.

Hypothesis II Is their evidence of top income/wealth shares following a U-shape or L-shape trend?

Apart from the Netherlands, all other countries show at least one trend break or a pure level shift. Where we find evidence of a trend break, we proceed to estimate the broken trends that characterise the historical data chosen in this study. Based on where a break, or two break points are located, we partition the sample into separate regimes and estimate linear trends for each regime using the robust methods as described in the previous section. The trend estimates for pre-break and post-break regimes are reported in Table 3. For those countries that exhibit two breaks, we partition the data in to three regimes, whereas for a single break case, the number of regimes is two. However, for meaningful estimates to be obtained, a sufficient number of observations is necessary for estimation of a trend in each regime. We set that minimum number to be thirty observations. In some of the cases where break points are found to be in the 1980s, the trend estimates for the post break regime may not be reported; simply because it is not possible to obtain meaningful estimates, as there are too few data points to obtain meaningful results. In the cases where we locate pure level shifts, the trend is estimated using first differenced specification. ${ }^{7}$ We report the associated $90 \%$ and $95 \%$ confidence intervals within parentheses along with the trend estimates. The results are summarised in Table 3.

The top 0.1 percentile income share for France does show a significant declining trend over the period 1915-1982. This period contains two regimes over which the trend is found to break; from 1915 to 1948 the trend declined at the rate of $3.6 \%$ and thereafter until 1982 at the rate of $1.1 \%$. The sharp decline from 1915 to 1948 reflects the assertion by Piketty that the wars had a huge impact on France with onethird of capital stock destroyed in World War I and then two-thirds in World War II (Piketty 2007, Vol I, p. 56). From 1982 to the end of the sample, that is 2017, we find no significant trend. While the estimate of the trend changes sign to being positive, the confidence intervals at the $95 \%$ and $90 \%$ levels contain zero, thereby

\footnotetext{
7 The first difference specification is used, as we later on show that these data series contain a unit root.
} 
Table 3 Robust trend estimation

\begin{tabular}{|c|c|c|c|}
\hline & Regime 1 & Regime 2 & Regime 3 \\
\hline \multicolumn{4}{|c|}{ Top $0.1 \%$ income share } \\
\hline Australia & $\begin{array}{l}-0.0173 * \\
90 \% \text { conf. interval } \\
(-0.0330,-0.0016) \\
95 \% \text { conf. interval } \\
(-0.0360,0.0014)\end{array}$ & $\begin{array}{l}0.0248 * * * \\
90 \% \text { conf. interval } \\
(0.0162,0.0335) \\
95 \% \text { conf. interval } \\
(0.0145,0.0351)\end{array}$ & \\
\hline Canada & Too few observations & $\begin{array}{l}-0.0285^{* * *} \\
90 \% \text { conf. interval } \\
(-0.0449,-0.0121) \\
95 \% \text { conf. interval } \\
(-0.0480,-0.0090)\end{array}$ & $\begin{array}{l}0.0232 \\
90 \% \text { conf. interval } \\
(-0.0025,0.0489) \\
95 \% \text { conf. interval } \\
(-0.0073,0.0537)\end{array}$ \\
\hline USA & $\begin{array}{l}-0.0262 * * \\
90 \% \text { conf. interval } \\
(-0.0443,-0.0080) \\
95 \% \text { conf. interval } \\
(-0.0478,-0.0046)\end{array}$ & $\begin{array}{l}0.0373 * * * \\
90 \% \text { conf. interval } \\
(0.0136,0.0610) \\
95 \% \text { conf. interval } \\
(0.0092,0.0654)\end{array}$ & \\
\hline France & $\begin{array}{l}-0.0364 * \\
90 \% \text { conf. interval } \\
(-0.0673 .-0.0056) \\
95 \% \text { conf. interval } \\
(-0.0731,0.0002)\end{array}$ & $\begin{array}{l}-0.0111^{* * *} \\
90 \% \text { conf. interval } \\
(-0.0171,-0.0051) \\
95 \% \text { conf. interval } \\
(-0.0182,-0.0039)\end{array}$ & $\begin{array}{l}0.0085 \\
90 \% \text { conf. interval } \\
(-0.0035,0.0206) \\
95 \% \text { conf. interval } \\
(-0.0057,0.0228)\end{array}$ \\
\hline Japan & $\begin{array}{l}-0.0084 \\
90 \% \text { conf. interval } \\
(-0.0234,0.0066) \\
95 \% \text { conf. interval } \\
(-0.0262,0.0094)\end{array}$ & & \\
\hline India & $\begin{array}{l}-0.0137 \\
90 \% \text { conf. interval } \\
(-0.0341,0.0067) \\
95 \% \text { conf. interval } \\
(-0.0379,0.0105)\end{array}$ & $\begin{array}{l}0.0340 * * * \\
90 \% \text { conf. interval } \\
(0.0298,0.0382) \\
95 \% \text { conf. interval } \\
(0.0290,0.0390)\end{array}$ & \\
\hline \multicolumn{4}{|c|}{ Top $1 \%$ income share } \\
\hline Australia & $\begin{array}{l}-0.0170 * \\
90 \% \text { conf. interval } \\
(-0.0323,-0.0017) \\
95 \% \text { conf. interval } \\
(-0.0352,0.0012)\end{array}$ & $\begin{array}{l}0.0168 * \\
90 \% \text { conf. interval } \\
(0.0008,0.0328) \\
95 \% \text { conf. interval } \\
(-0.0022,0.0358)\end{array}$ & \\
\hline Canada & $\begin{array}{l}-0.0006 \\
90 \% \text { conf. interval } \\
(-0.0105,0.0093) \\
95 \% \text { conf. interval } \\
(-0.0123,0.0111)\end{array}$ & & \\
\hline New Zealand & $\begin{array}{l}-0.0033 \\
90 \% \text { conf. interval } \\
(-0.0201,0.0135) \\
95 \% \text { conf. interval } \\
(-0.0232,0.0166)\end{array}$ & & \\
\hline
\end{tabular}


Table 3 (continued)

\begin{tabular}{|c|c|c|c|}
\hline & Regime 1 & Regime 2 & Regime 3 \\
\hline USA & $\begin{array}{l}-0.0089 * * * \\
90 \% \text { conf. interval } \\
(-0.0124,-0.0055) \\
95 \% \text { conf. interval } \\
(-0.0130,-0.0049)\end{array}$ & $\begin{array}{l}0.0162 * * \\
90 \% \text { conf. interval } \\
(0.0055,0.0270) \\
95 \% \text { conf. interval } \\
(0.0034,0.0290)\end{array}$ & \\
\hline Japan & $\begin{array}{l}-0.0048 \\
90 \% \text { conf. interval } \\
(-0.0194,0.0098) \\
95 \% \text { conf. interval } \\
(-0.0222,0.0126)\end{array}$ & & \\
\hline India & $\begin{array}{l}-0.0062 \\
90 \% \text { conf. interval } \\
(-0.0271,0.0147) \\
95 \% \text { conf. interval } \\
(-0.0310,0.0187)\end{array}$ & $\begin{array}{l}0.0318 * * * \\
90 \% \text { conf. interval } \\
(0.0279,0.0357) \\
95 \% \text { conf. interval } \\
(0.0272,0.0364)\end{array}$ & \\
\hline France & $\begin{array}{l}-0.0056 \\
90 \% \text { conf. interval } \\
(-0.0154,0.0043) \\
95 \% \text { conf. interval } \\
(-0.0173,0.0061)\end{array}$ & & \\
\hline Sweden & $\begin{array}{l}-0.0169 * * \\
90 \% \text { conf. int } \\
(-0.0243,-0.0095) \\
95 \% \text { conf. int } \\
(-0.0256,-0.0081)\end{array}$ & Too few observations & $\begin{array}{l}0.0254 * * \\
90 \% \text { conf. int } \\
(0.0216,0.0291) \\
95 \% \text { conf. int } \\
(0.0209,0.0298)\end{array}$ \\
\hline Norway & $\begin{array}{l}-0.0150 * * \\
90 \% \text { conf. int } \\
(-0.0212,-0.0088) \\
95 \% \text { conf. int } \\
(-0.0224,-0.0076)\end{array}$ & Too few observations & \\
\hline Netherlands & $\begin{array}{l}-0.0186^{* *} \\
90 \% \text { conf. int } \\
(-0.0252,-0.0120) 95 \% \text { conf. } \\
\text { int } \\
(-0.0264,-0.0108)\end{array}$ & N/A & N/A \\
\hline Finland & $\begin{array}{l}-0.0108 \\
90 \% \text { conf. int } \\
(-0.0274,0.0057) \\
95 \% \text { conf. int } \\
(-0.0305,0.0088)\end{array}$ & Too few observations & Too few observations \\
\hline \multicolumn{4}{|c|}{ Top $10 \%$ income share } \\
\hline USA & $\begin{array}{l}0.001 \\
90 \% \text { conf. interval } \\
(-0.0023,0.0043) \\
95 \% \text { conf. interval } \\
(-0.0029,0.0050)\end{array}$ & & \\
\hline France & $\begin{array}{l}-0.0037 \\
90 \% \text { conf. interval } \\
(-0.0084,0.001) \\
95 \% \text { conf. interval } \\
(-0.0093,0.0019)\end{array}$ & & \\
\hline
\end{tabular}


Table 3 (continued)

\begin{tabular}{|c|c|c|c|}
\hline & Regime 1 & Regime 2 & Regime 3 \\
\hline \multicolumn{4}{|c|}{ Top $1 \%$ wealth share } \\
\hline USA & $\begin{array}{l}-0.0103 \\
90 \% \text { conf. interval } \\
(-0.0215,0.0009) \\
95 \% \text { conf. interval } \\
(-0.0236,0.0030)\end{array}$ & $\begin{array}{l}0.0137 * * * \\
90 \% \text { conf. interval } \\
(0.0057,0.0217) \\
95 \% \text { conf. interval } \\
(0.0043,0.0231)\end{array}$ & \\
\hline France & $\begin{array}{l}-0.0072 * \\
90 \% \text { conf. interval } \\
(-0.0141,-0.0003) \\
95 \% \text { conf. interval } \\
(-0.0154,0.001)\end{array}$ & & \\
\hline UK & $\begin{array}{l}-0.0089 * * * \\
90 \% \text { conf. interval } \\
(-0.0118,-0.0059) 95 \% \text { conf. } \\
\text { interval } \\
(-0.0124,-0.0053)\end{array}$ & $\begin{array}{l}-0.02720 * * * \\
90 \% \text { conf. interval } \\
(-0.0330,-0.0209) \\
95 \% \text { conf. interval } \\
(-0.0342,-0.0198)\end{array}$ & Too few observations \\
\hline \multicolumn{4}{|c|}{ Top $10 \%$ wealth share } \\
\hline USA & $\begin{array}{l}-0.0031 \\
90 \% \text { conf. interval } \\
(-0.0071,0.0010) \\
95 \% \text { conf. interval } \\
(-0.0078,0.0017)\end{array}$ & $\begin{array}{l}0.0049 * * \\
90 \% \text { conf. interval } \\
(0.0017,0.0081) \\
95 \% \text { conf. interval } \\
(0.0011,0.0087)\end{array}$ & \\
\hline France & $\begin{array}{l}-0.0037 * * \\
90 \% \text { conf. interval } \\
(-0.0063,-0.0011) \\
95 \% \text { conf. interval } \\
(-0.0068,-0.0006)\end{array}$ & & \\
\hline UK & $\begin{array}{l}-0.0028 * * * \\
90 \% \text { conf. interval } \\
(-0.0042,-0.0014) \\
95 \% \text { conf. interval } \\
(-0.0044,-0.0011)\end{array}$ & $\begin{array}{l}-0.0135 * * * \\
90 \% \text { conf. interval } \\
(-0.0169,-0.0101) \\
95 \% \text { conf. interval } \\
(-0.0175,-0.0095)\end{array}$ & Too few observations \\
\hline
\end{tabular}

\footnotetext{
******,and *denote significance at the $1 \%, 5 \%$ and $10 \%$ levels, respectively. The trend estimates are reported with the associated confidence intervals in parentheses
}

rendering the estimate to be insignificant. The large variability around this estimated trend cannot preclude us from concluding that the estimate is significantly different from zero. In the case of Canada, we do not have enough observations to obtain a meaningful trend from 1920 to 1933 . However, from 1933 to 1971 , we find a significant negative trend, and thereafter the trend becomes insignificant. A broken trend (V-shape) is found for Australia and USA. The decline and subsequent rise in top income shares are estimated to be statistically significant. For India, the apparent decline in the trend is insignificant from 1922 to 1977, but then increases at the statistically significant rate of $3.4 \%$ thereafter. In the case of Japan, we find a level shift, a sharp drop in top income shares at 1944, which shows the impact of World War II on top income shares, mainly because of a fall in capital income due to inflation and war time regulations and destruction (Moriguchi and Saez 2010). 
The overall long-run trend in the top income share for Japan is found to be insignificant; all we find is a precipitous drop due to the war. The lack of any increasing or decreasing inequality at least for the first half of the twentieth century suggests that the Great Depression did not have much of an impact on Japan (Moriguchi and Saez 2010) compared to Australia, USA and France. We find top income shares have risen significantly in USA, but no such significant rise is found for Canada since the early 1970 s.

When considering the top $1 \%$ income shares, we continue to find evidence of a V-shape trend for Australia and USA. In the case of Australia, the rate of income inequality decline for the top $1 \%$ is broadly similar to the top $0.1 \%$ decline (around $1.7 \%$ ). However, the rate of top $1 \%$ increase in inequality for Australia is relatively slow $(1.6 \%)$ compared to the top $0.1 \%$ income share $(2.4 \%)$. In the case of top $1 \%$ income shares of USA, we find a flatter V-shape trend, with both the rate of decline and increase being relatively slower. Piketty (2007, p.11) attributes the rise of USA top income shares to the very large increases in top wages, especially the salaries to top executives. Our results suggest that this faster rate of increase of the relatively very rich (top $0.1 \%$ ) could be due to the very high compensation of executives belonging to this group. Our results depart from the observations made by Atkinson and Leigh (2013) of a common U-shaped time path for Anglo-Saxon countries.

In the case of India, comparing $0.1 \%$ and $1 \%$ top income shares we find the trend estimates are very similar across the two regimes. We can conclude the underlying factors that may have caused the trend break applies to both the top $0.1 \%$ and $1 \%$ income shares. However, the rate of income inequality increases since the $1970 \mathrm{~s}$ is higher for the top $0.1 \%$ income share in comparison with the top $1 \%$ income share. Canada and France display different dynamics when comparing the top $1 \%$ and $0.1 \%$ income shares. We find evidence of trend breaks for the top $0.1 \%$, with two trend breaks occurring in the first half and the second half of the twentieth century. However, in the case of the top $1 \%$ income share we only find a level shift in the 1940s with both Canada and France showing no significant increase or decrease in inequality over the entire sample period. Sweden, Norway and Netherlands show a declining trend for most part of the twentieth century. Finland, in comparison with its Nordic neighbours, does not show any significant trend. We find four countries (Australia, USA, Japan and India) to display similar individual trends when comparing cross the top percentile groups (that is, $0.1 \%$ and $1 \%$ ). When comparing the top $1 \%$ and $10 \%$ income shares, only France, displays an insignificant trend. In the case of the USA, while the top $0.1 \%$ and $1 \%$ have a V-shape broken trend, there is no significant trend for the top $10 \%$ income share. This may be explained by the level break that we find for the top $10 \%$ income share in the USA. The 'Great Compression' a term due to Goldin and Margo (1992) describes the narrowing of the wage gap in the USA after the war in the 1940s.

Our results support the recent study by Bengtsson and Waldenström (2018) where they report that there are quite large differences in the level of income, and variations in the time trends of income shares, and in the composition of income across sources of different earners within the top decile as well as the top percentile group. Bengtsson and Waldenström (2018) point out that this is in contrast to past studies that top income earners are similar to each other. While Roine and 

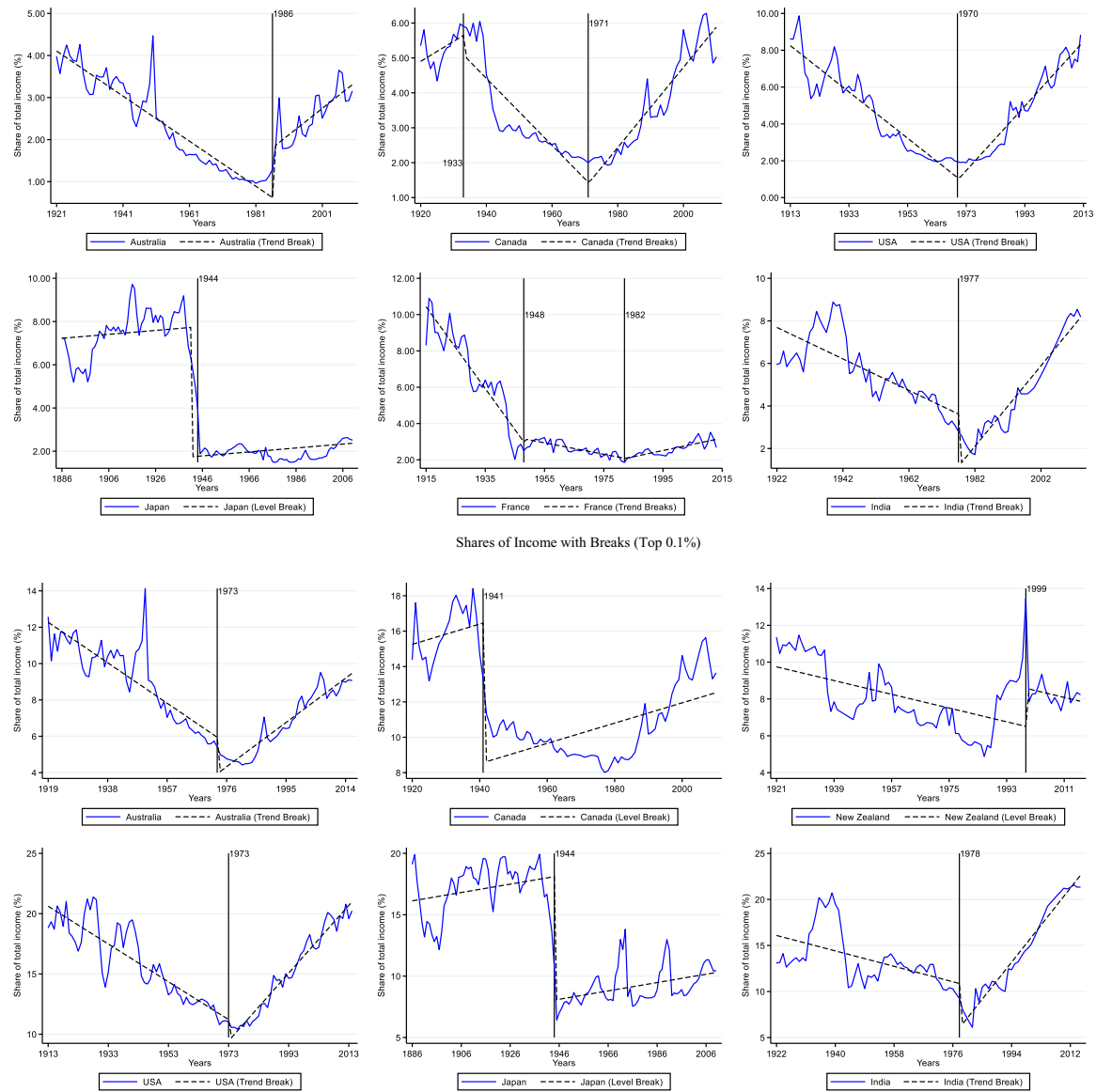

Shares of Income with Breaks (Top 1\%)
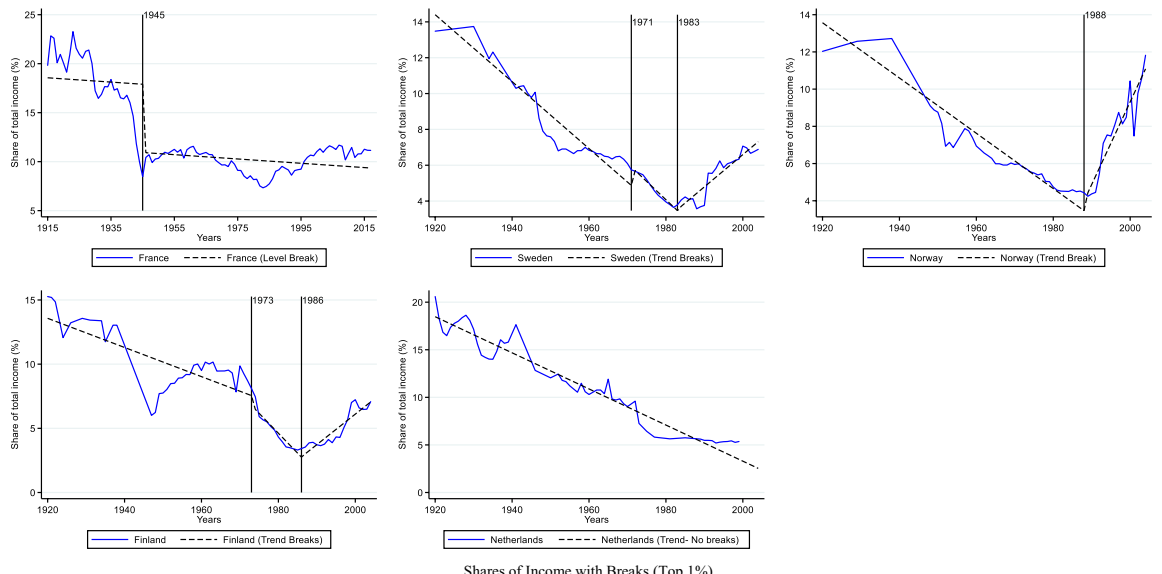

Fig. 1 a Shares of income with breaks (Top 0.1\%). b Shares of income with breaks (Top 1\%). c Shares of income with breaks (Top 10\%) 

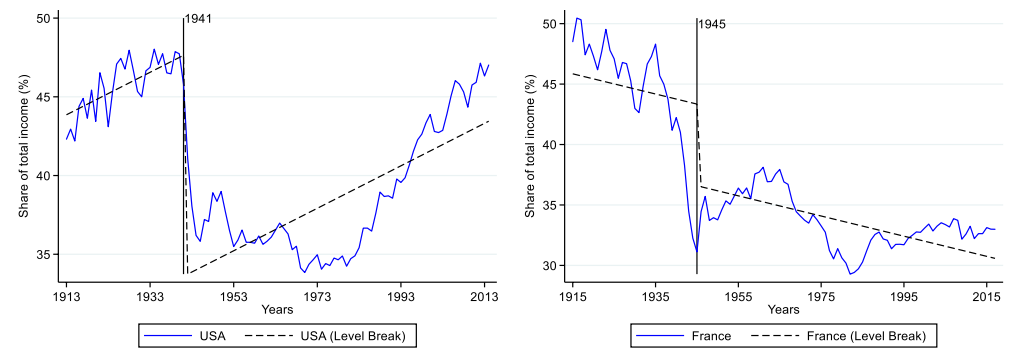

Shares of Income with Breaks (Top 10\%)

Fig. 1 (continued)

Waldenström (2015) describe inequality in Japan and India to display similar trends (p.495), our trend estimates give a very contrasting picture. However, while Atkinson et al. (2011) describe most countries (Anglo-Saxon, European, Asian) to record a fall in top income shares until around 1980; our results show that we find this to be true for only some Anglo-Saxon and European countries, but not for the Asian countries. Again, Atkinson et al. (2011) notes Anglo-Saxon countries and India to record an increase in top income shares from around 1980. We find partial evidence of the top percentile for Anglo-Saxon countries (Australia and USA), but no clear evidence for countries such as Canada or New Zealand; however, India shows an increasing trend since the late 1970s. In the case of Sweden, we find a negative trend from 1920 to 1971, which contrasts with Finland showing an insignificant trend during the same period. The trends of the top $0.1 \%, 1 \%$ and $10 \%$ income shares for the different regimes demarcated by the structural breaks are shown in Fig. 1.

Moving to wealth inequality, we find similar trends for each country when comparing the top $1 \%$ and $10 \%$ wealth shares. For example, in the case of the UK, top wealth shares are found to decline in the first half of the twentieth century, after which the rate of decline increases until the mid-1980s. Thereafter, while we do detect a trend break, there are too few observations to determine a trend from the mid-1980s to the end of the sample, that is, 2003. In the case of the USA, we find that for both top $1 \%$ and $10 \%$ shares, there is no trend until the late 1970 s and early 1980s. This absence of trend may be caused by the significant amount of variability in wealth concentration, where it peaked before the Great Depression and then declined until the point where the trend started to increase again (Kopczuk 2015). From the point we detect a trend break for USA, the top shares of wealth inequality have been increasing, and the rate of increase of the top $1 \%$ exceeds that of the top $10 \%$. A possible explanation might be the scaling back of the estate tax since the 1970s in the USA (Kopczuk 2015). Further, this surge in wealth inequality for the top $1 \%$ as well as the top $10 \%$ nests around the period when the USA went through financial deregulation. In the case of UK, we find the decline in wealth shares accelerating since the 1950s until the 1980s. Possible explanations could be the accumulation of assets by those below the top capital strata, as well as the introduction of death duties that may have encouraged wealth owners to distribute their wealth thereby creating smaller holdings (Feinstein 1996). The change in trend since 1986 

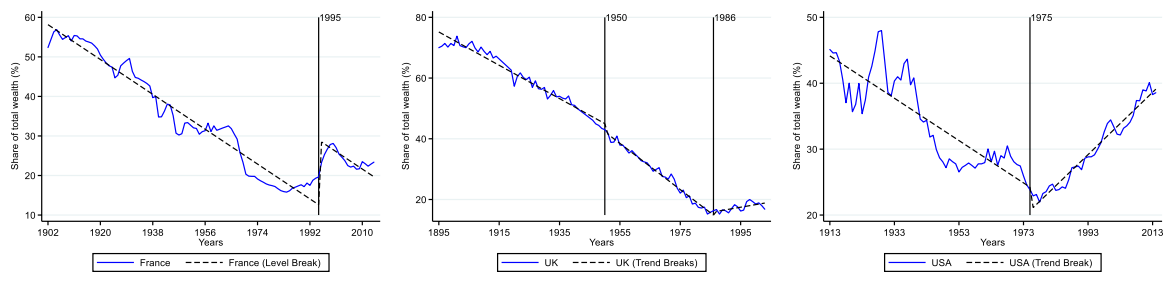

Shares of Wealth with Breaks (Top 1\%)
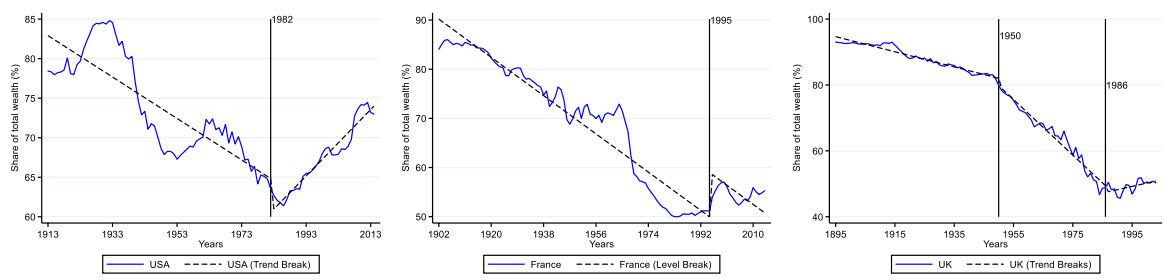

Shares of Wealth with Breaks (Top 10\%)

Fig. 2 Shares of Wealth with Breaks (Top 1\%). b Shares of wealth with breaks (Top 10\%)

coincides with the financial market reforms or the so called 'Big Bang' that took place in the UK (Tanndal and Waldenström 2018). Finally, for France we find a secular decline and a relatively faster rate $(0.72 \%)$ of decline for the top $1 \%$ wealth shares than the estimated decline of $0.37 \%$ for the top $10 \%$ wealth share. Alvaredo et al. (2017) note that the share of inheritance of aggregate private wealth in the UK and France was initially high up to 1910, and then gradually fell since then until the 1980s.

To sum up, we find that almost all countries are characterised by broken trends, or level shifts. The preponderance of trend breaks appears in the 1970s and 1980s where after a negative trend changes direction to either becoming positive or insignificant, or with too few observations to draw a reasonable conclusion. In the case of income shares, a V shape trend seems to appear for Australia and USA for the top percentile shares, and a significant positive trend is found since the 1970s for these countries as well as India across all income groups of the top percentile. We do not find any econometric support for a U-shape trend, but that could be largely due to the scarcity of data. Within the top percentile, there is weak evidence of an L-shape trend for France, Canada, Sweden and Norway. ${ }^{8}$ Due to the absence of a long continual data for Nordic countries we can only conclude that for most part of the twentieth century inequality has been declining though not significantly for Finland. Comparing across the top $1 \%$ and top $10 \%$ wealth shares, the individual dynamics are similar for the UK and USA, and France. The trends of the top $1 \%$

\footnotetext{
${ }^{8}$ We note 'weak' in the sense that while a downward trend is discernible, the no trend for the remaining part of the sample is not estimates Sweden and Norway as too few observations were available for any meaningful estimation.
} 
Table 4 Unit root tests for top income and wealth shares

\begin{tabular}{|c|c|c|c|c|c|}
\hline & $\mathrm{MZ}_{\mathrm{a}}$ & $\mathrm{MZ}_{\mathrm{t}}$ & MSB & MPT & $\mathrm{PT}$ \\
\hline \multicolumn{6}{|c|}{ Top $0.1 \%$ income share } \\
\hline Australia & -10.518 & -2.227 & 0.212 & 15.779 & 15.995 \\
\hline Canada & -9.004 & -2.115 & 0.235 & 22.723 & 22.437 \\
\hline France & -17.047 & -2.913 & 0.171 & 11.176 & 9.692 \\
\hline India & -1.903 & -0.726 & 0.381 & 47.929 & 48.804 \\
\hline USA & -2.729 & -0.882 & 0.323 & 48.865 & 40.329 \\
\hline Japan & -5.171 & -1.568 & 0.303 & 46.18 & 41.195 \\
\hline \multicolumn{6}{|c|}{ Top $1 \%$ income share } \\
\hline Australia & -8.148 & -1.856 & 0.228 & 22.37 & 20.21 \\
\hline Canada & -3.435 & -1.203 & 0.35 & 40.443 & 40.602 \\
\hline New Zealand & -12.593 & -2.472 & 0.196 & 11.068 & 9.694 \\
\hline USA & $-23.792 * *$ & $-3.439 * *$ & $0.145^{* *} *$ & $6.804 * *$ & $6.546^{* *}$ \\
\hline Japan & -8.424 & -2.02 & 0.24 & 19.616 & 19.523 \\
\hline India & -8.489 & -2.058 & 0.242 & 18.516 & 16.637 \\
\hline Netherlands & -6.073 & -1.611 & 0.265 & 18.59 & 14.906 \\
\hline France & -3.88 & -1.256 & 0.324 & 44.182 & 37.85 \\
\hline Sweden & -6.767 & -1.809 & 0.267 & 33.469 & 30.618 \\
\hline Norway & -10.837 & -2.327 & 0.215 & 11.541 & 10.896 \\
\hline Finland & -5.521 & -1.614 & 0.292 & 41.396 & 41.605 \\
\hline \multicolumn{6}{|c|}{ Top $10 \%$ income shares } \\
\hline USA & -2.362 & -0.883 & 0.374 & 53.848 & 52.456 \\
\hline France & -4.115 & -1.296 & 0.315 & 42.115 & 35.945 \\
\hline \multicolumn{6}{|c|}{ Top $1 \%$ wealth shares } \\
\hline USA & -6.767 & -1.756 & 0.26 & 23.088 & 23.349 \\
\hline France & -4.493 & -1.33 & 0.296 & 29.493 & 29.963 \\
\hline UK & -7.131 & -1.835 & 0.257 & 31.115 & 31.383 \\
\hline \multicolumn{6}{|c|}{ Top $10 \%$ wealth shares } \\
\hline USA & -11.25 & -2.371 & 0.211 & 15.898 & 14.495 \\
\hline France & -6.847 & -1.7 & 0.248 & 22.789 & 21.192 \\
\hline UK & -7.745 & -1.968 & 0.254 & 29.257 & 27.352 \\
\hline
\end{tabular}

**denotes rejection of the null hypothesis at the $5 \%$ significance level

and $10 \%$ wealth shares for the regimes demarcated by structural breaks are shown in Fig. 2.

Hypothesis III Do we find evidence of persistent inequality?

Following the results in Table 1, we employ the unit root procedures to test for persistence of inequality. We test whether shocks to top income shares are permanent or transitory in nature. Apart for the Netherlands, all other countries with different income share categories contain at least one break in the slope or a pure level 
shift. Accordingly, for Netherlands, the M-class test proposed by Elliott et al. (1996) and $\mathrm{Ng}$ and Perron (2001) is applied, whereas for all the other countries we perform the modified tests proposed by Carrion-i-Silvestre et al. (2009). The results of the tests are reported in Table 4.

The results of the unit root tests show that we are unable to reject the null hypothesis of a unit root for all the selected countries across all the top income and wealth shares with the exception of USA for the top $1 \%$ income share. For each of the unit root tests we compute the bootstrapped critical values, which can be found in Table 5 in Appendix. We carry out a range of tests, that include the Point Optimal $\left(P_{T}\right)$ tests and the M-class tests $\left(M Z_{a}, M Z_{t}, M S B, M P_{T}\right)$, and in each case (apart for the top 1\% income share of the USA) we find the estimated test statistic to be insignificant to reject the unit root null. The results imply that shocks to top income shares are not transitory in nature. Our results lend support to the conclusions of persistence made by Christopoulos and McAdam (2017).

\section{Conclusion}

This paper adds to the literature on the long-run evolution of top income shares by testing three hypotheses. First, we test for structural breaks in the series using robust methods that allow us to be agnostic about the order of integration of the data series. Secondly, using the using robust methods we fit linear trends to regimes demarcated by structural breaks; that is, we estimate the trends in the inequality series for the pre-break and/or inter-break, and post-break regimes. Finally, we test for persistence, that is, whether shocks to inequality are transitory or not, allowing for the symmetric treatment of structural breaks in the inequality series. Through testing these hypotheses, we obtain the dynamics of the top income and wealth shares for a reasonably long period of time, at least using almost a century of continuous time series data.

The structural break tests are insightful as they show a preponderance of trend breaks around the 1970s and 1980s for the top percentile income share. This coincides with many countries adopting a fiscal policy of tax cuts albeit to varying degrees, as well as a surge in wage incomes. This is true for USA, Australia, and India for the top percentile income shares. In the case of Japan we find level shifts around the mid-1940s, thereby realising the immediate impact that was felt in the aftermath of World War II for the top $0.1 \%$ as well as the top $1 \%$. The same impact was felt by the top $10 \%$ in USA and France.

It has been argued that technology shifts that are skills biased can change the trend of inequality. We see some evidence of this, that there is a change in the trend for Anglo-Saxon countries such as Australia and USA, and the arresting of a negative trend for France. Other European countries may have followed a similar path to France, such as Sweden, Norway and the Netherlands, but there are too few observations following the location of the trend break to make a meaningful inference. However, we can say that in general there is a change in the underlying negative trend, prevalent for a large part of the twentieth century around the 1970s and 1980s. While we cannot be definitive whether the trend 
in recent years is significantly positive or not for all countries, we are reasonable sure that there has been a change in trend from around the early 1980s. A possible explanation for this finding might be the view expressed that the introduction of assembly lines may have caused a decrease in inequality while the ICT revolution led to an increase in inequality, or an arrest to the decline in inequality. The timing however, may be different, longer in countries such as New Zealand and Netherlands, in comparison with Sweden and Finland, which is not completely unexpected as technological changes do not take place at the same time around the world due to adoption lags (Comin and Mestieri 2013). Besides our results show that skill-biased technology alone cannot explain the diverging patterns in the high-income countries; rather institutional factors and policy differences may have played a part (Alvaredo et al. 2013). The financial deregulation and privatisation that occurred in the USA and UK coincide with the break in the trend found for the top wealth shares in those countries. This result suggests that the growth of the financial sector during this time may have contributed to the change in the trend of wealth inequality, which had not been increasing over time prior to the 1980s. In general, the time path of top income and wealth shares are different for individual countries, and cannot be aggregated in to groups such as Anglo-Saxon or Nordic or Asian, as countries within such a group do not exhibit common dynamics.

Finally, a test is carried out on how persistent shocks are to the top income shares. We find that using unit root tests that allow for structural breaks the conclusion is clearly in favour of inequality being highly persistent to shocks. This view is contrary to that of Islam and Madsen (2015) but supports the conclusions of Christopoulos and McAdam (2017). If regression based analysis on long-run top income or wealth share data is to be carried out, then the country specific characteristics may need to be accounted for given the possibility of structural breaks and the underlying persistence that are found to exist in the data. One could argue that the major shocks such as the World Wars and the Great Depression had a persistent effect on income inequality, since the high taxes had a persistent effect on capital owners, affecting their wealth and income. Holter (2015) documents several reasons why persistence may exist in top income shares, which include the returns to investment in human capital, progressive taxation, and the presence of credit constraints. The finding of persistent inequality can have consequences for distributional mobility and there may be a need for policy intervention.

\section{Appendix}

See Table 5. 
Table 5 Unit root tests critical values

\begin{tabular}{|c|c|c|c|c|c|c|}
\hline Series & Level (\%) & $\mathrm{MZ}_{\mathrm{a}}$ & $\mathrm{MZ}_{\mathrm{t}}$ & MSB & PT & MPT \\
\hline \multicolumn{7}{|c|}{ Top 0.1 income share } \\
\hline \multirow[t]{3}{*}{ Australia } & 10 & -20.071 & -3.136 & 0.157 & 7.847 & 7.847 \\
\hline & 5 & -23.579 & -3.41 & 0.145 & 6.57 & 6.57 \\
\hline & 1 & -32.19 & -3.977 & 0.125 & 4.654 & 4.654 \\
\hline \multirow[t]{3}{*}{ Canada } & 10 & -24.449 & -3.462 & 0.141 & 8.6 & 8.6 \\
\hline & 5 & -28.511 & -3.751 & 0.131 & 7.253 & 7.253 \\
\hline & 1 & -37.196 & -4.292 & 0.115 & 5.44 & 5.44 \\
\hline \multirow[t]{3}{*}{ France } & 10 & -20.432 & -3.171 & 0.154 & 8.29 & 8.29 \\
\hline & 5 & -24.014 & -3.447 & 0.142 & 6.948 & 6.948 \\
\hline & 1 & -32.098 & -3.983 & 0.124 & 5.008 & 5.008 \\
\hline \multirow[t]{3}{*}{ India } & 10 & -19.48 & -3.096 & 0.16 & 7.377 & 7.377 \\
\hline & 5 & -23.131 & -3.378 & 0.148 & 6.186 & 6.186 \\
\hline & 1 & -31.537 & -3.93 & 0.127 & 4.424 & 4.424 \\
\hline \multirow[t]{3}{*}{ United States } & 10 & -18.491 & -3.029 & 0.159 & 8.611 & 8.611 \\
\hline & 5 & -22.118 & -3.324 & 0.145 & 7.213 & 7.213 \\
\hline & 1 & -28.969 & -3.819 & 0.127 & 5.179 & 5.179 \\
\hline \multirow[t]{3}{*}{ Japan } & 10 & -24.952 & -3.509 & 0.14 & 9.016 & 9.016 \\
\hline & 5 & -28.955 & -3.785 & 0.13 & 7.711 & 7.711 \\
\hline & 1 & -37.423 & -4.312 & 0.115 & 5.85 & 5.85 \\
\hline \multicolumn{7}{|c|}{ Top 1 income share } \\
\hline \multirow[t]{3}{*}{ Australia } & 10 & -19.297 & -3.086 & 0.158 & 8.845 & 8.845 \\
\hline & 5 & -23.005 & -3.386 & 0.144 & 7.338 & 7.338 \\
\hline & 1 & -28.167 & -3.788 & 0.128 & 5.537 & 5.537 \\
\hline \multirow[t]{3}{*}{ Canada } & 10 & -19.988 & -3.137 & 0.157 & 7.875 & 7.875 \\
\hline & 5 & -23.615 & -3.416 & 0.145 & 6.604 & 6.604 \\
\hline & 1 & -31.831 & -3.958 & 0.125 & 4.771 & 4.771 \\
\hline \multirow[t]{3}{*}{ France } & 10 & -20.41 & -3.169 & 0.155 & 8.264 & 8.264 \\
\hline & 5 & -23.985 & -3.444 & 0.143 & 6.925 & 6.925 \\
\hline & 1 & -32.107 & -3.983 & 0.124 & 4.983 & 4.983 \\
\hline \multirow[t]{3}{*}{ India } & 10 & -19.14 & -3.071 & 0.161 & 7.556 & 7.556 \\
\hline & 5 & -22.801 & -3.359 & 0.148 & 6.31 & 6.31 \\
\hline & 1 & -30.344 & -3.873 & 0.128 & 4.566 & 4.566 \\
\hline \multirow[t]{3}{*}{ United States } & 10 & -19.065 & -3.067 & 0.16 & 8.307 & 8.307 \\
\hline & 5 & -22.744 & -3.364 & 0.146 & 6.897 & 6.897 \\
\hline & 1 & -28.661 & -3.803 & 0.128 & 5.135 & 5.135 \\
\hline \multirow[t]{3}{*}{ Japan } & 10 & -17.506 & -2.944 & 0.165 & 9.588 & 9.588 \\
\hline & 5 & -21.153 & -3.262 & 0.147 & 7.833 & 7.833 \\
\hline & 1 & -23.307 & -3.548 & 0.133 & 6.078 & 6.078 \\
\hline \multirow[t]{3}{*}{ New Zealand } & 10 & -19.6 & -3.073 & 0.163 & 6.252 & 6.252 \\
\hline & 5 & -22.996 & -3.331 & 0.152 & 5.236 & 5.236 \\
\hline & 1 & -34 & -4.021 & 0.127 & 3.474 & 3.474 \\
\hline Netherlands & 10 & -14 & -2.607 & 0.186 & 6.78 & 6.78 \\
\hline
\end{tabular}


Table 5 (continued)

\begin{tabular}{|c|c|c|c|c|c|c|}
\hline Series & Level (\%) & $\mathrm{MZ}_{\mathrm{a}}$ & $\mathrm{MZ}_{\mathrm{t}}$ & MSB & PT & MPT \\
\hline & 5 & -17.326 & -2.896 & 0.168 & 5.544 & 5.544 \\
\hline & 1 & -24.485 & -3.471 & 0.142 & 3.833 & 3.833 \\
\hline \multirow[t]{3}{*}{ Finland } & 10 & -25.975 & -3.588 & 0.138 & 9.145 & 9.145 \\
\hline & 5 & -29.952 & -3.851 & 0.129 & 7.884 & 7.884 \\
\hline & 1 & -38.434 & -4.366 & 0.114 & 5.965 & 5.965 \\
\hline \multirow[t]{3}{*}{ Norway } & 10 & -16.793 & -2.887 & 0.172 & 7.174 & 7.174 \\
\hline & 5 & -20.334 & -3.181 & 0.156 & 5.94 & 5.94 \\
\hline & 1 & -27.39 & -3.7 & 0.134 & 4.2 & 4.2 \\
\hline \multirow[t]{3}{*}{ Sweden } & 10 & -24.557 & -3.495 & 0.142 & 8.592 & 8.592 \\
\hline & 5 & -28.445 & -3.763 & 0.132 & 7.34 & 7.34 \\
\hline & 1 & -36.996 & -4.292 & 0.116 & 5.492 & 5.492 \\
\hline \multicolumn{7}{|c|}{ Top 10 income share } \\
\hline \multirow[t]{3}{*}{ France } & 10 & -20.41 & -3.169 & 0.155 & 8.264 & 8.264 \\
\hline & 5 & -23.985 & -3.444 & 0.143 & 6.925 & 6.925 \\
\hline & 1 & -32.107 & -3.983 & 0.124 & 4.983 & 4.983 \\
\hline \multirow[t]{3}{*}{ United States } & 10 & -19.112 & -3.072 & 0.159 & 8.842 & 8.842 \\
\hline & 5 & -22.815 & -3.373 & 0.145 & 7.324 & 7.324 \\
\hline & 1 & -27.73 & -3.766 & 0.128 & 5.537 & 5.537 \\
\hline \multicolumn{7}{|l|}{ Top 1 wealth share } \\
\hline \multirow[t]{3}{*}{ United States } & 10 & -20.369 & -3.165 & 0.155 & 8.124 & 8.124 \\
\hline & 5 & -23.951 & -3.441 & 0.143 & 6.811 & 6.811 \\
\hline & 1 & -32.237 & -3.986 & 0.124 & 4.906 & 4.906 \\
\hline \multirow[t]{3}{*}{ France } & 10 & -19.541 & -3.103 & 0.159 & 7.806 & 7.806 \\
\hline & 5 & -23.203 & -3.389 & 0.146 & 6.529 & 6.529 \\
\hline & 1 & -30.822 & -3.904 & 0.127 & 4.748 & 4.748 \\
\hline \multirow[t]{3}{*}{ United Kingdom } & 10 & -24.875 & -3.52 & 0.14 & 9.192 & 9.192 \\
\hline & 5 & -29.094 & -3.805 & 0.129 & 7.914 & 7.914 \\
\hline & 1 & -36.882 & -4.287 & 0.115 & 5.983 & 5.983 \\
\hline \multicolumn{7}{|c|}{ Top 10 wealth share } \\
\hline \multirow[t]{3}{*}{ United States } & 10 & -18.557 & -3.027 & 0.161 & 9.027 & 9.027 \\
\hline & 5 & -22.242 & -3.334 & 0.146 & 7.437 & 7.437 \\
\hline & 1 & -26.192 & -3.689 & 0.13 & 5.675 & 5.675 \\
\hline \multirow[t]{3}{*}{ France } & 10 & -19.583 & -3.106 & 0.159 & 7.787 & 7.787 \\
\hline & 5 & -23.243 & -3.391 & 0.146 & 6.517 & 6.517 \\
\hline & 1 & -30.969 & -3.911 & 0.127 & 4.732 & 4.732 \\
\hline \multirow[t]{3}{*}{ United Kingdom } & 10 & -24.076 & -3.463 & 0.143 & 8.819 & 8.819 \\
\hline & 5 & -28.108 & -3.744 & 0.133 & 7.534 & 7.534 \\
\hline & 1 & -36.219 & -4.252 & 0.117 & 5.642 & 5.642 \\
\hline
\end{tabular}


Acknowledgements The authors would like to thank Mohitosh Kejriwal and Carrion-i-Silvestre for sharing their codes. Javier Ordóñez gratefully acknowledges financial support from the Agencia Estatal de Investigación (Spain) and Fondo Europeo de Desarrollo Regional (AEI/FEDER ECO2017-83,255-C33-P Project), the Generalitat Valenciana project PROMETEO/2018/102., and the University Jaume I research project UJI-B2017-33. The usual disclaimer applies.

\section{Declarations}

Conflict of interest The authors declare that they have no conflict of interest.

Ethical approval This article does not contain any studies with human participants or animals performed by any of the authors.

Open Access This article is licensed under a Creative Commons Attribution 4.0 International License, which permits use, sharing, adaptation, distribution and reproduction in any medium or format, as long as you give appropriate credit to the original author(s) and the source, provide a link to the Creative Commons licence, and indicate if changes were made. The images or other third party material in this article are included in the article's Creative Commons licence, unless indicated otherwise in a credit line to the material. If material is not included in the article's Creative Commons licence and your intended use is not permitted by statutory regulation or exceeds the permitted use, you will need to obtain permission directly from the copyright holder. To view a copy of this licence, visit http://creativecommons.org/licen ses/by/4.0/.

\section{References}

Alvaredo F, Atkinson AB, Piketty T, Saez E (2013) The top 1 percent in international and historical perspective. J Econ Perspect 27(3):3-20

Alvaredo F, Garbinti B, Piketty T (2017) On the share of inheritance in aggregate wealth: Europe and the USA, 1900-2010. Economica 84(334):239-260

Alvaredo F, Atkinson AB, Morelli S (2018) Top wealth shares in the UK over more than a century. J Public Econ 162:26-47

Andrews DWK (1993) Tests for parameter instability and structural change with unknown change point. Econometrica 61(4):821-856

Andrews DWK, Ploberger W (1994) Optimal tests when a nuisance parameter is present only under the alternative. Econometrica 62(6):1383-1414

Atkinson AB (2005) Top Incomes in the UK over the 20th Century. J R Stat Soc A Stat Soc 168(2):325-343

Atkinson AB, Leigh A (2007) The distribution of top incomes in Australia. Econ Rec 83(262):247-261

Atkinson AB, Piketty T (eds) (2007) Top incomes over the twentieth century: a contrast between continental European and English-speaking countries. OUP Oxford

Atkinson AB (2008) The changing distribution of earnings in OECD countries Oxford and New York. Oxford University Press, Oxford

Atkinson AB, Piketty T (eds) (2010) Top Incomes: a global perspective. Oxford University Press, Oxford

Atkinson AB, Leigh A (2013) The Distribution of top incomes in five Anglo-Saxon countries over the long run. Econ Rec 89(S1):31-47

Atkinson AB, Piketty T, Saez E (2011) Top Incomes in the long run of history. J Econ Lit 49(1):3-71

Bai J, Carrion-i-Silvestre JL (2009) Structural changes, common stochastic trends, and unit roots in panel data. Rev Econ Stud 76(2):471-501

Bai J, Perron P (1998) Estimating and testing linear models with multiple structural changes. Econometrica $66: 47-78$

Bai J, Perron P (2003) Computation and analysis of multiple structural change models. J Appl Economet $18: 1-22$ 
Bengtsson E, Waldenström D (2018) Capital shares and income inequality: evidence from the long run. J Econ Hist 78(3):712-743

Bricker J, Henriques A, Krimmel J, Sabelhaus J (2016) Measuring income and wealth at the top using administrative and survey data. Brook Pap Econ Act 2016:261-331

Burkhauser RV, Feng S, Jenkins SP, Larrimore J (2012) Recent trends in top income shares in the United States: reconciling estimates from March CPS and IRS tax return data. Rev Econ Stat 94(2):371-388

Campbell JY, Perron P (1991) Pitfalls and opportunities: what macroeconomists should know about unit roots. NBER Macroecon Annu 6:141-201

Carrion-i-Silvestre JL, Del Barrio-Castro T, López-Bazo E (2005) Breaking the panels: an application to the GDP per capita. Econom J 8(2):159-175

Carrion-i-Silvestre JL, Kim D, Perron P (2009) GLS-based unit root tests with multiple structural breaks under both the null and the alternative hypotheses. Econom Theor 25(6):1754-1792

Caselli F (1999) Technological revolutions. Am Econ Rev 89(1):78-102

Chancel L, Piketty T (2019) Indian Income Inequality, 1922-2015: From British Raj to Billionaire Raj? Rev Income Wealth 65:S33-S62

Christopoulos D, McAdam P (2017) On the persistence of cross-country inequality measures. J Money, Credit, Bank 49(1):255-266

Comin DA, Mestieri M (2013) Technology diffusion: measurement, causes and consequences (No. w19052). National Bureau of Economic Research

Dollar D, Kraay A (2002) Spreading the wealth. Foreign Aff 81:120-133

Elliott G, Rothenberg T, Stock J (1996) Efficient tests for an autoregressive unit root. Econometrica 64:813-836

Feinstein C (1996) The equalizing of wealth in Britain since the Second World War. Oxf Rev Econ Policy 12(1):96-105

Firebaugh G (2003) The new geography of global income inequality. Harvard University Press, Cambridge, MA

Ghoshray A, Kejriwal M, Wohar M (2014) Breaks, trends and unit roots in commodity prices: a robust investigation. Stud Nonlinear Dyn Econom 18(1):23-40

Goldin C, Margo RA (1992) The great compression: the wage structure in the United States at midcentury. Quart J Econ 107(1):1-34

Harvey DI, Leybourne SJ, Taylor AMR (2009) Simple, robust, and powerful tests of the breaking trend hypothesis. Economet Theor 25(4):995-1029

Harvey DI, Leybourne SJ, Taylor AMR (2010) Robust methods for detecting multiple level breaks in autocorrelated time series. J Econom 157(2):342-358

Harvey DI, Leybourne SJ, Taylor AMR (2013) Testing for unit roots in the possible presence of multiple trend breaks using minimum Dickey-Fuller statistics. J Econom 177(2):265-284

Holter HA (2015) Accounting for cross-country differences in intergenerational earnings persistence: the impact of taxation and public education expenditure. Quant Econ 6(2):385-428

Islam MR, Madsen JB (2015) Is income inequality persistent? Evidence using panel stationarity tests, 1870-2011. Econ Lett 127:17-19

Jäntti M, Riihelä M, Sullström R, Tuomala M (2010) Trends in top income shares in Finland. Top Incomes Global Perspect 2

Kejriwal M, Perron P (2010) A sequential procedure to determine the number of breaks in trend with an integrated or stationary noise component. J Time Ser Anal 31:305-328

Kopczuk W (2015) What do we know about the evolution of top wealth shares in the United States? J Econ Perspect 29(1):47-66

Krueger A (2012) The rise and consequences of inequality. Presentation made to the Center for American Progress in Washington, DC, January

Kuznets S (1955) Economic growth and income inequality. Am Econ Rev 45(1):1-28

Kuznets S, Jenks E (1953) Shares of upper income groups in savings. In: Shares of upper income groups in income and savings. NBER, pp 171-218

Kwiatkowski D, Phillips PC, Schmidt P, Shin Y (1992) Testing the null hypothesis of stationarity against the alternative of a unit root. J Econom 54(1-3):159-178

Leybourne S, Mills T, Newbold P (1998) Spurious rejections by Dickey-Fuller tests in the presence of a break under the null. J Econom 87:191-203

Lumsdaine RL, Papell DH (1997) Multiple trend breaks and the unit-root hypothesis. Rev Econ Stat 79(2):212-218 
Maddala GS, Wu S (1999) A comparative study of unit root tests with panel data and a new simple test. Oxford Bull Econ Stat 61(S1):631-652

Mokyr J (1990) The lever of riches: technological creativity and economic progress. Oxford University Press, Oxford

Moriguchi C, Saez E (2010) The evolution of income concentration in Japan, 1886-2005. Top incomes: a global perspective. Oxford University Press, Oxford , pp 76-170

Murphy KJ (1999) Executive compensation. In: Ashenfelter O, Card D (eds) Handbook of labor economics, vol 3. North-Holland, Amsterdam

Murphy B, Roberts P, Wolfson M (2007) High-income Canadians. Perspect Labour Income 19(4):7

Ng S, Perron P (2001) Lag length selection and the construction of unit root tests with good size and power. Econometrica 69:1519-1554

Perron P (1988) Trends and random walks in macroeconomic time series: Further evidence from a new approach. J Econ Dyn Control 12(2-3):297-332

Perron P (1989) The great crash, the oil price shock, and the unit root hypothesis. Econometrica 57:1361-1401

Perron P, Rodríguez G (2003) GLS detrending, efficient unit root tests and structural change. J Econom 115(1):1-27

Perron P, Yabu T (2009a) Testing for shifts in trend with an integrated or stationary noise component. J Bus Econ Stat 27:369-396

Perron P, Yabu T (2009b) Estimating deterministic trends with an integrated or stationary noise component. J Econom 151:56-69

Piketty T (2003) Income inequality in France, 1901-1998. J Polit Econ 111(5):1004-1042

Piketty T (2005) Top income shares in the long run: an overview. J Eur Econ Assoc 3(2-3):1-11

Piketty T (2007) Income inequality in France. In: Atkinson AB, Piketty T (eds) Top incomes over the twentieth century: a contrast between european and english-speaking countries. Oxford University Press, Oxford, pp 1900-1998

Piketty T (2014) Capital in the twenty-first century. Harvard University Press. (Translated by A. Goldhammer)

Piketty T, Saez E (2003) Income inequality in the United States, 1913-1998. Q J Econ 118(1):1-41

Piketty T, Saez E (2014) Inequality in the Long Run". Science 344(6186):838-843

Piketty T, Saez E, Stantcheva S (2014) Optimal taxation of top labor incomes: a tale of three elasticities. Am Econ J Econ Pol 6(1):230-271

Qu Z, Perron P (2007) Estimating and testing structural changes in multivariate regressions. Econometrica 75:459-502

Roine J, Waldenström D (2008) The evolution of top incomes in an egalitarian society: Sweden, 19032004. J Public Econ 92(1-2):366-387

Roine J, Waldenström D (2011) Common trends and shocks to top incomes: a structural breaks approach. Rev Econ Stat 93:832-846

Roine J, Waldenström D (2015) Long-run trends in the distribution of income and wealth. In: Atkinson AB, Bourguignon F (eds) Handbook of income distribution, 2(A). Elsevier B.V, USA, pp 469-592

Roine J, Vlachos J, Waldenström D (2009) The long-run determinants of inequality: what can we learn from top income data? J Public Econ 93(7):974-988

Rosen S (1981) The economics of superstars. Am Econ Rev 71(5):845-858

Roy A, Fuller WA (2001) Estimation for autoregressive time series with a root near 1. J Bus Econ Stat 19(4):482-493

Saez E, Veall MR (2005) The evolution of high incomes in Northern America: lessons from Canadian evidence. Am Econ Rev 95(3):831-849

Saez E, Veall MR (2007) The Evolution of High Incomes in Canada, 1920-2007. In: Atkinson A, Piketty $\mathrm{T}$ (ed) Top incomes over the twentieth century: a contrast between continental European and English-speaking countries. OUP Oxford. pp 226-308

Saez E, Zucman G (2016) Wealth inequality in the United States since 1913: evidence from capitalized income tax data. Q J Econ 131(2):519-578

Tanndal J, Waldenström D (2018) Does financial deregulation boost top incomes? Evidence from the big bang. Economica 85(338):232-265

Veall MR (2010) 2B or not 2B? What should have happened with the Canadian long form census? What should happen now? Can Public Policy 36(3):395-399

Veall MR (2012) Top income shares in Canada: recent trends and policy implications. Can J Econ Rev 45(4):1247-1272 
Vogelsang TJ (1998) Trend function hypothesis testing in the presence of serial correlation. Econometrica $66: 123-148$

Wade RH (2004) Is globalization reducing poverty and inequality? World Dev 32(4):567-589

Zivot E, Andrews D (1992) Further evidence on the great crash, the oil price shock and the unit root hypothesis. J Bus Econ Stat 10:251-270

Zucman G (2019) Global wealth inequality. Ann Rev Econ 11:109-138 